\title{
Evaluation of Selected Dam-Break Flood-Wave Models by Using Field Data
}

U.S. GEOLOGICAL SURVEY

Water-Resources Investigations 80-44

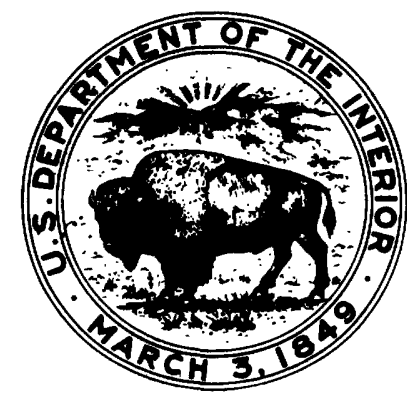




\section{REPORT DOCUMENTATION PAGE}

4. Title and Subtitle

EVALUATION OF SELECTED DAM-BREAK FLOOD-WAVE MODELS BY USING FIELD DATA

7. Author(s)

Larry F. Land

9. Performing Organization Name and Address

U.S. Geological Survey, Water Resources Division

Gulf Coast Hydroscience Center

National Space Technology Laboratories

NSTL Station, MS 39529

12. Sponsoring Organization Name and Address

U.S. Geological Survey, Water Resources Division

Gulf Coast Hydroscience Center

National Space Technology Laboratories

NSTL Station, MS 39529

15. Supplementary Notes

16. Abstract (Limit: 200 words)

Four dam-break flood-wave models have been evaluated by using three field data sets and selected criteria of desirable features. The models include (1) modified Puls (MP), (2) U.S. Army Corps of Engineers' unsteady flow profiles (USTFIO), (3) National Weather Services' dam-break flood forecast (DBFF), and (4) U.S. Geological Survey's coupled metho of characteristics and a general purpose streamflow simulation (MOC-J879DB). The field data sets documented the disasters at Teton Dam, Idaho, Laurel Run, Pa., and Toccoa Falls, Ga.

The computed discharges were often within 20 percent of the observed values with the exception of the simulations at Teton Dam and for a short distance below the dams by the MOC-J879DB. With the same exceptions noted above, the computed flood crests were usually within 2 feet of the observed high-water marks.

A modified version of the DBFF model is identified as the most accurate, economical, flexible, numerically stable, easiest to apply, and descriptive of the boundary and flow conditions.

17. Document Analysis a. Descriptors

*Dam failure, *Floods, *Model studies, Mathematical models, Hydraulic properties, Hydrodynamics, Continuity equations, Momentum equations, Flood routing

b. Identifiers/Open-Ended Terms

Teton Dam, Idaho, Laurel Run, Pennsylvania, Toccoa Falls, Georgia

c. COSATI Field/Group

18. Availability Statement

No restriction on distribution.

19. Security Class (This Report)

UNCIASSIFIED

20. Security Class (This Page)

UNCI,ASSIFIED 
EVALUATION OF SELECTED DAM-BREAK FLOOD-WAVE MODELS BY USING FIELD DATA

By Larry F. Land

U.S. GEOLOGICAL SURVEY

Water-Resources Investigations 80-44

July 1980 


\section{UNITED STATES DEPARTMENT OF THE INTERIOR \\ CECIL D. ANDRUS, Secretary}

GEOLOGICAL SURVEY

H. William Menard, Director

For additional information write to:

U.S. Geological Survey, WRD Gulf Coast Hydroscience Center National Space Technology Laboratories NSTL Station, MS 39529 


\section{CONTENTS}

Page

Conversion table- VI

Abstract--

Introduction--

Method of investigation-

Selection of models- 2

Field data sets-- 3

Teton Dam, Idaho-- 3

Johnstown, $\mathrm{Pa} .-(5$

Toccoa Falls, Ga._- 5

Features of dam-break models- 8

Mathematical models- 9

MP model- 9

USTFLO model- 11

DBFF model-- 12

MOC-J879DB models--- 14

Characterization of test cases- 17

Teton Dam-- 18

MP model-- 18

USTFLO model- 19

DBFF model- 19

MOC-J879DB models- 19

Johnstown-- 20

MP model-- 20

DBFF model- 20

MOC-J879DB models- 21

Toccoa Falls-- 21

MP model- 22

DBFF model- 22

MOC-J879DB models- 22

Results--

Teton Dam-- 23

Discharges- 23

Flood profile- 25

Traveltime-- 25

Johnstown-- 28

Discharges- 28

Flood profile-n-n-m 28

Traveltime-- 28

Toccoa Falls-- 33

Discharges--n- 33

Flood profile- 33

Traveltime-- 33

Discussion--

Identification of general-purpose model- 39

Summary- 39

References cited-- 41 


\section{ILLUSTRATIONS}

Page

Figures 1-3. Maps showing location of:

1. Teton Dam, Idaho, study area-- 4

2. Laurel Run, Pa., study area-....... 6

3. Toccoa Falls, Ga., study area-------- 7

4. Graphs showing observed and computed peak

discharges along Teton River- 24

5. Hydrographs showing computed discharge for

three sites along Teton River-- 26

6. Graphs showing observed and computed high-water marks along Teton River-- 27

7. Graphs showing observed and computed peak discharges along Laurel Run--- 29

8. Hydrographs showing computed discharge for three sites along Laurel Run- 30

9-11. Graphs showing:

9. Observed high-water marks and computed crests for the upper part of Laurel Run--_-

10. Observed high-water marks and computed crests for the lower part of Laurel Run

11. Observed and computed peak discharges along Toccoa Creek-

12. Hydrographs showing computed discharge for three sites along Toccoa Creek

13. Graphs showing the observed high-water marks and computed crests for the upper part of Toccoa Creek--_-_-_-_-

14. Graphs showing the observed high-water marks and computed crests for the lower part of

Toccoa Creek-_- 
TABLES

Page

Table 1. Flow into the three reservoir-stream systems------- 43

2. Relationship of elevation-storage-surface areaoutflow for the three reservoirs- 44

3. Channel characteristic and geometry data coded in the GEDA format for the Teton Dam reservoirstream system--

4. Channel characteristic and geometry data coded in the GEDA format for the Laurel Run reservoirstream system--

5. Channel characteristic and geometry data coded in the GEDA format for the Toccoa Falls reservoirstream system--

6. Code format and variable definitions of the data given in tables 3-5 
FACTORS FOR CONVERTING U.S. INCH-POUND UNITS

TO SI UNITS

Multiply U.S. inch-pound units

$\underline{B y}$

To obtain SI units

foot ( $f t$ )

0.3048

meter (m)

mile (mi)

1.609

kilometer $(\mathrm{km})$

acre

0.4047

square mile $\left(m i^{2}\right)$

2.590

square hectometer $\left(\mathrm{hm}^{2}\right)$

acre-foot (acre-ft)

0.001233

square kilometer $\left(\mathrm{km}^{2}\right)$

cubic foot per second $\left(f t^{3} / s\right)$

0.02832

cubic hectometer $\left(\mathrm{hm}^{3}\right)$

cubic meter per second $\left(\mathrm{m}^{3} / \mathrm{s}\right)$ 


\author{
EVALUATION OF SELECTED DAM-BREAK \\ FLOOD-WAVE MODELS BY USING FIELD DATA \\ By Larry F. Land
}

\begin{abstract}
Four dam-break flood-wave models have been evaluated by using three field data sets and selected criteria of desirable features. The models include (1) modified Puls (MP), (2) U.S. Army Corps of Engineers' unsteady flow profiles (USTFLO), (3) National Weather Services' dambreak flood forecast (DBFF), and (4) U.S. Geological Survey's coupled method of characteristics and a general purpose streamflow simulation (MOC-J879DB). The field data sets documented the disasters at Teton Dam, Idaho, Laurel Run, Pa., and Toccoa Falls, Ga.

The computed discharges were often within 20 percent of the observed values with the exception of the simulations at Teton Dam and for a. short distance below the dams by the MOC-J879DB. With the same exceptions noted above, the computed flood crests were usually within 2 feet of the observed high-water marks.

A modified version of the DBFF model is identified as the most. accurate, economical, flexible, numerically stable, easiest to apply, and descriptive of the boundary and flow conditions.
\end{abstract}

\title{
INTRODUCTION
}

Delineating the extent of flooding caused by a dam failure is one aspect of flood mapping that has had limited attention. However, the disasters in the last few years have caused an increased awareness of this potential flood hazard. As a result, the federal government is requiring the inspection of dams that potentially threaten life and property. Repairs or alterations must be made to the ones that lack structural integrity and the ability to handle large storms. For dams that pose a special threat to the public, engineering studies are conducted to determine the extent of flooding which would result from a hypothetical failure. This latter activity is the major subject of: this report.

Predicting the extent of flooding, including floods caused by dam failures, is one of the activities of the U.S. Geological Survey. The primary tool for making the predictions or analyzing a dam-break flood is a mathematical model that can simulate the reservoir-stream system. Several models have been developed and are available. However, the best model for general-use applications has not been identified. As a result, an investigation was conducted to evaluate several mathematical 
models in order to identify the best one. The criteria for model evaluation were several desirable dam-break model features and the model's ability to accurately simulate field occurrences. The desirable features included such items as requiring only readily available data, having numerical stability and accuracy, simulating flow on hydraulically mild or steep slopes, and having simplicity, flexibility and economy. The field data sets available for model testing were the occurrences at Teton Dam, Idaho on June 5, 1976, Johnstown, Pa. on July 19-20, 1977, and at Toccoa Falls, Ga. on November 5-6, 1977.

\section{METHOD OF INVESTIGATION}

\section{Selection of Models}

Numerous models could have been included in this evaluation; however, the scope of the investigation limited the number to four tested and documented models. The selected models ranged in technical sophistication from a straightforward hydrologic routing model to a complex hydraulic routing model that incorporates shock-wave equations. In the order of complexity, the selected models included a hydrologic model that uses the modified Puls technique and hydraulic models that use an explicit finite-difference technique, a nonlinear finite-difference technique, and a coupled method-of-characteristics and linear implicit finitedifference techniques.

The simplest and least mathematically rigorous model uses a modified Puls (MP) routing technique. Sources of such programs include the U.S. Army Corps of Engineers (1973) and a Survey unpublished report (U.S. Geological Survey, written commun., 1978). The Survey model was selected because it was readily available and, if needed, it could be easily revised to handle special dam-break problems. The next model is the Corps of Engineers' (1977) Gradually Varied Unsteady Flow Profiles (USTFLO) model. It is a general purpose streamflow simulation model that can be used for a dam-break flood wave simulation by the use of certain options and model layouts. The model uses the complete flow equations with an explicit leap-frog finite-difference algorithm. The third model was developed by Fread (1977) of the National Weather Service specifically for application to dam breaks. This dam-break flood forecast (DBFF) model uses a nonlinear implicit finite-difference algorithm to solve the complete flow equations. The last dam-break flood wave simulation model, developed by the Survey (Chen and Druffel, 1977), couples an explicit method-of-characteristics (MOC) model that includes the shock wave simulation with a general-purpose (J879DB) model using a linear implicit finite-difference alogrithm. The MOC model is used until the shock wave nearly dissipates and the simulation is completed with the J879DB model. 
The availability of data sets documenting a dam-break flood and describing the reservoir-stream system is limited. Three of the best data sets are for the occurrences at Teton Dam, Idaho, Johnstown, Pa., and Toccoa Falls, Ga. The Teton Dam data are mostly in a report by Ray and Kjelstrom (1978). The published Johnstown data are in the reports by Armbruster (1978) and Chen and Armbruster (1979). The published Toccoa Falls data are mostly in reports by a Federal Investigative Board (1977), Sanders and Sauer (1979), and Land (1978a). In all cases, additional data were supplied by the local Survey offices.

For those readers interested in the details of these three field data sets, much of these data are listed in the following tables. The presented data include: (1) flow into the reservoir-stream systems (table 1), (2) reservoir elevation-storage-surface area-outflow information (table 2), and (3) reservoir-stream system geometry along with highwater marks (tables 3,4, and 5). Table 6 is given to show the code format and variable definition for the geometry data in tables 3-5. The data presented in tables 3-5 have been coded in the GEDA program format; however, only data related to the channel description are given except for the variable HWM which has been added (field 10) to the XI card. It is the observed high-water mark at that cross section. If the data are estimated, an asterisk (*) precedes the value. If an entire cross section is estimated, an * is placed in front of the X1 card. A complete definition of the coded data is given in the GEDA documentation by the U.S. Army Corps of Engineers (1976).

Teton Dam, Idaho

The failure of Teton Dam on the Teton River, Idaho (fig. 1) on June 5, 1976 released 251,700 acre-ft of water stored behind the 305-ft high and 1,200-ft long earth-filled structure. At the time of failure, the reservoir's water level was at an altitude of $5,301.7 \mathrm{ft}$, about 272 ft above the streambed. The altitude of the dam's crest was 5,330 ft with a spillway crest of 5,305 ft. The first evidence of the dam.'s impending failure was noticed at 7:30 a.m. on June 5. The dam was breached at 11:57 a.m. The almost fully penetrating breach, approximately trapezoidal in shape, included about 40 percent of the dam. The failure was not associated with any current flooding on the river; in fact, it was being filled for the first time. A detailed field survey of the breach was not available. As a result, the breach's dimensions were estimated from topographic maps and photographs. For purposes of this report the breach was assumed to have eroded to an elevation of 5,040 $\mathrm{ft}$, and to have a base width of $50 \mathrm{ft}$ and side slopes of 1.52:1.00 (horizontal to vertical). 


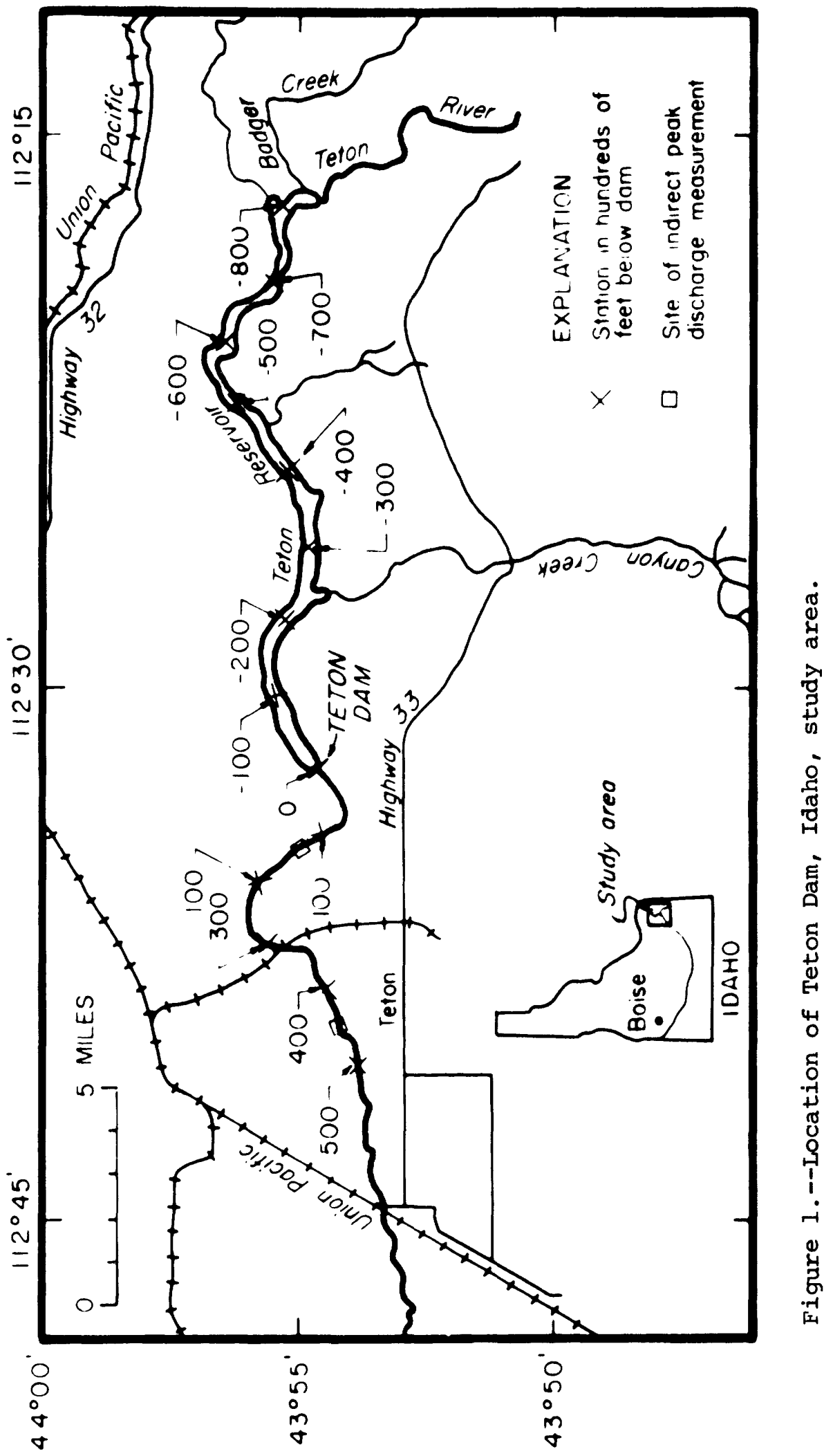


Teton Reservoir was formed in a canyon generally less than 1,200 ft wide. At high stages it was about $15 \mathrm{mi}$ long. Below the dam the canyon extended another $5 \mathrm{mi}$ before emptying into a valley or flood plain over $2 \mathrm{mi}$ wide. In the flood plain, Teton River widely meanders and divides about $8.5 \mathrm{mi}$ downstream of the dam into two forks which also meander considerably. Several stream diversions also exist in this area. For purposes of this investigation the flood wave was routed only about $9 \mathrm{mi}$ below the dam. Adaptation of the models to the complexity of the stream system below this point is beyond the scope of this study.

\section{Johnstown, Pennsylvania}

The failure of the Laurel Run Reservoir Dam near Johnstown, Pa. (fig. 2) released about 450 acre-ft of water in only a few minutes into a stream that was already flooding from a severe rainstorm. The earthen dam had a crest altitude of $1,436.5 \mathrm{ft}$ with a spillway crest of 1,430 ft. The streambed altitude was 1,391 ft. The estimated time of failure was $2: 35 \mathrm{a} . \mathrm{m}$. on July 20 , with the reservoir's water level at an altitude of 1,437.2 ft. Chen and Armbruster (1979) suspect that the dam had a partial failure before approximately one-third of the dam failed. The breach's shape was approximately triangular. It fully penetrated the dam and had average side slopes of 2.45:1.00.

The reservoir was about $0.4 \mathrm{mi}$ long and generally less than $600 \mathrm{ft}$ wide. The stream channel confined the flood to a width of less than 500 $\mathrm{ft}$, often less than $200 \mathrm{ft}$. Laurel Run flows into the Conemaugh River $2.5 \mathrm{mi}$ below the dam. Red Run and Wildcat Run Tributaries enter Laurel Run 1,100 and $9,700 \mathrm{ft}$ below the dam, respectively.

\section{Toccoa Falls, Georgia}

The dam-break flood at Toccoa Falls, Ga. (fig. 3) resulted from the failure of the dam forming Kelly Barnes Lake. The breach completely penetrated the dam, was $57 \mathrm{ft}$ wide at the base, and had average side slopes of $0.56: 1.00$. The time of failure was estimated to be 1:30 a.m. on November 6,1977 . It followed a series of rainstorms that had produced an estimated 7.2 in. of rain in the previous four days.

According to a Federal Investigative Report (1977), Kelly Barnes Dam had its origin as a rock crib dam in 1899. The dam was made larger in the late 1930's by building an earthen dam over the old rock crib dam. In the late 1940's the dam was made somewhat larger by adding earth to the structure. The base of the dam had an altitude of 1,102.0 ft. The normal pool altitude was 1,137 ft, the lower spillway's crest was $1,136.7 \mathrm{ft}$, the upper spillway's crest was $1,139.8 \mathrm{ft}$, and the crest of the dam was approximately 1,147 ft. Surveys show that the maximum water level for this flood was $1,141.6 \mathrm{ft}$, but the Federal Investigative Board believes that a series of partial failures lowered the water level to $1,137.5 \mathrm{ft}$ before the dam completely collapsed. The dam was about $400 \mathrm{ft}$ long and $20 \mathrm{ft}$ wide at the crest; the lake was about $0.9 \mathrm{mi}$ long. 


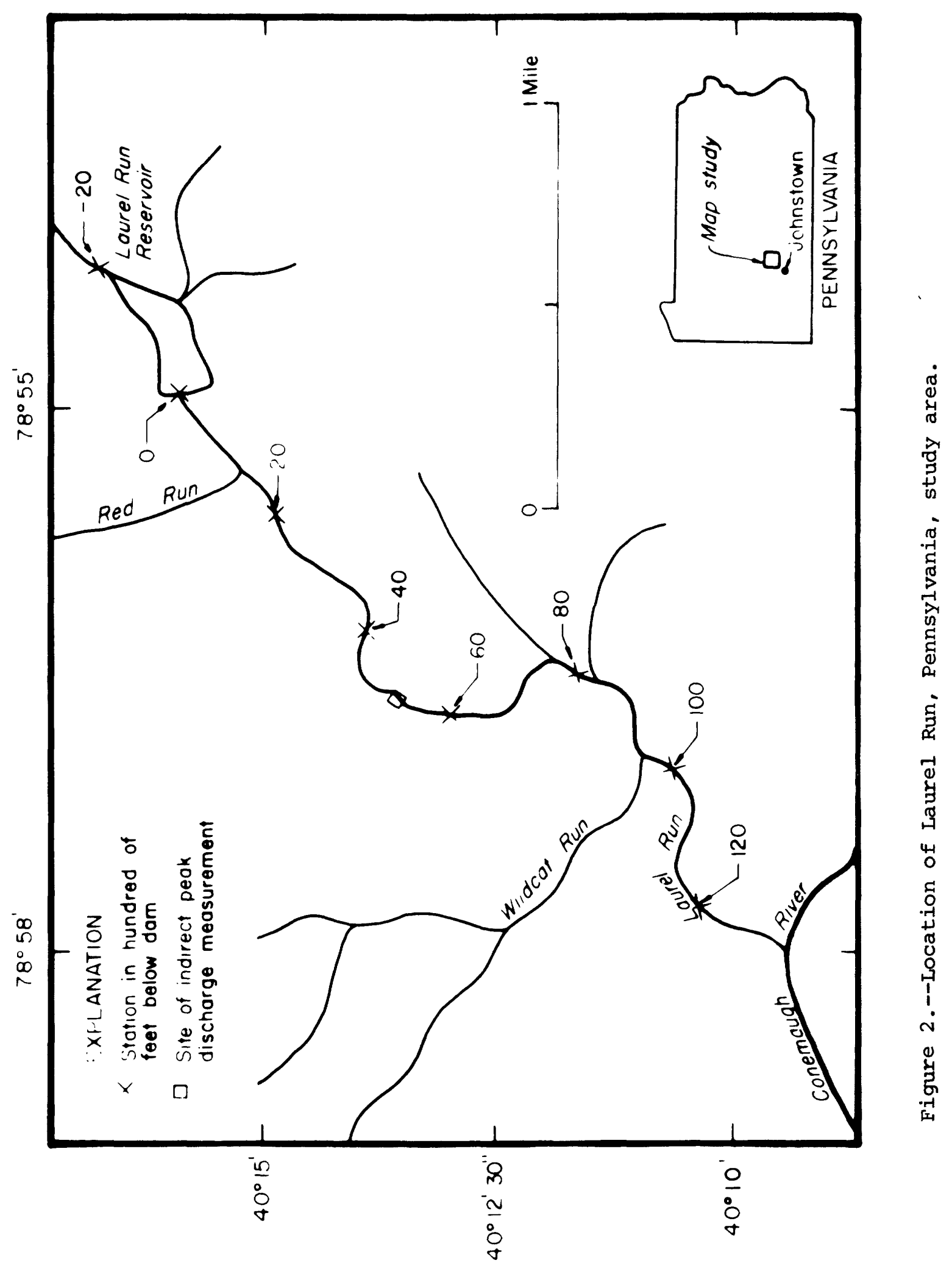




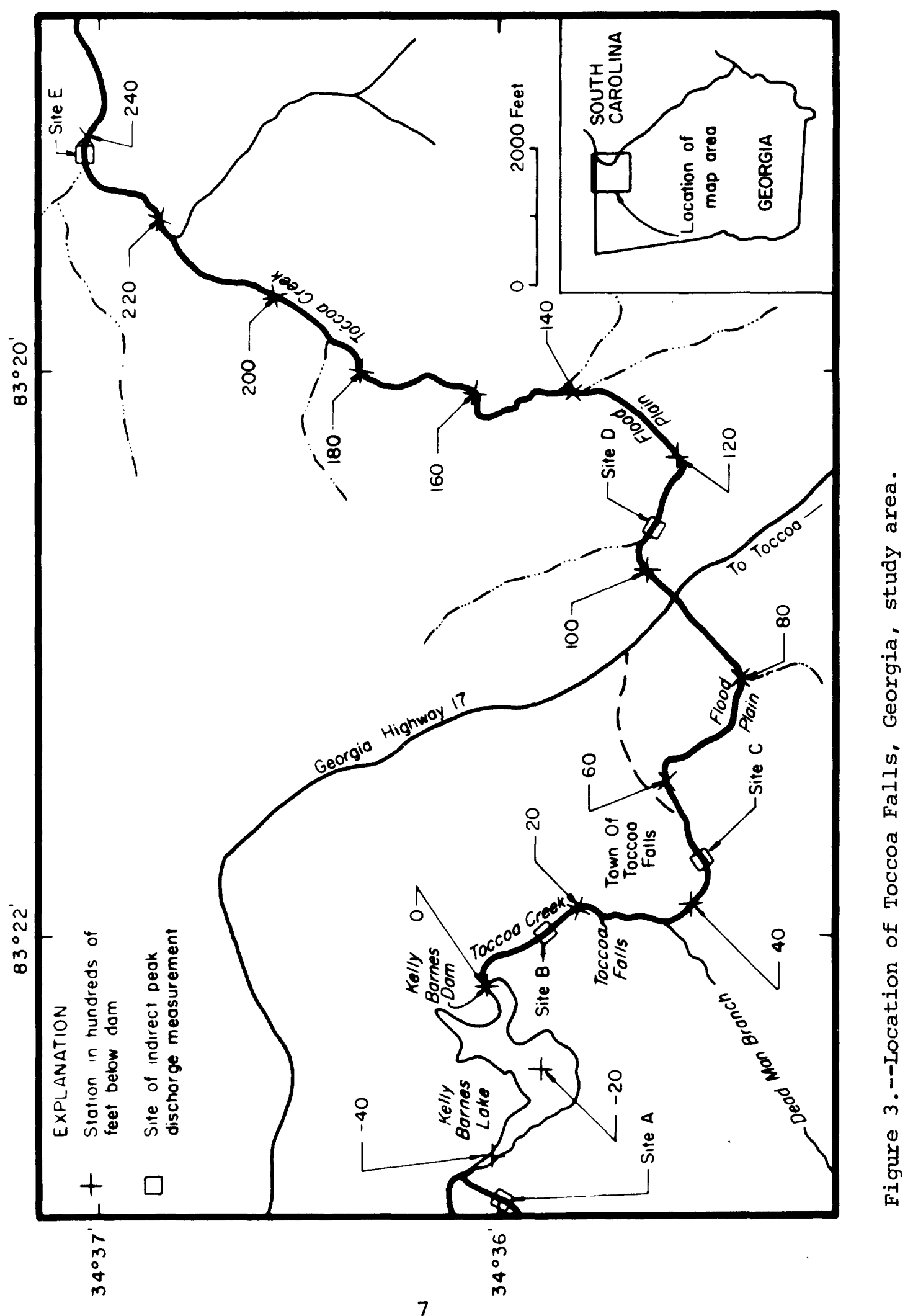


Toccoa Creek's headwaters are in the steep to very steep mountainous terrain of the Blue Ridge Mountains. After only a few miles, and 2,600 ft below Kelly Barnes Dam, the creek passes over the 175-ft Toccoa Falls and enters the foothills where the streambed is not as steep as in the mountains. In the reach above the falls the banks restricted the flood to a width of $300 \mathrm{ft}$. Below the falls the width of flooding was less than $500 \mathrm{ft}$ except in the wider parts of the flood plain where the width of flooding was as much as $1,000 \mathrm{ft}$. The flooding was surveyed for a distance of $4.4 \mathrm{mi}$ below the dam.

\section{FEATURES OF DAM-BREAK MODELS}

A researcher or engineer has many choices and approaches that can be taken in developing a dam-break flood model. The first choice is the basic type of model, that is, hydrologic or hydraulic. A hydrologic model uses the law of continuity, or its equivalent, in conjunction with the relationship between storage, inflow and outflow from the reach as they relate to time. This type of model is generally simpler, numerically more stable and easier to apply. A hydraulic model is based on the solution of the two partial differential equations describing unsteady flow in shallow open channels. This type of model uses equations that are known as the St. Venant equations, namely the equations of continuity and motion. For the extra effort in achieving a soluition, this type is generally more accurate and better describes the reservoir-stream system. Following the selection of the basic model type, several solution techniques or methods are available for each. For a hydrologic model the choice may include Muskingum, modified Puls, or kinematic wave methods. For the hydraulic model the numerical analysis technique may be any number of finite-difference, method-of-characteristics, or finite-element methods.

In the design of a general-purpose dam-break model other basic decisions are also necessary. Alternatives are: (1) to assume the dam failure to be instantaneous or to have a finite duration, (2) to treat the dam as an internal node that may or may not have special boundary conditions, or as a downstream boundary, (3) to simulate the shock front or ignore it, and (4) to route the flood wave in a wet or dry streambed. No matter what choices are made in the model's basic structure, it is desirable for the model to:

(1) Require only data readily available, or easily interpreted, from field surveys;

(2) Represent the complexity of the reservoir-stream system, including the conveyance and storage areas of channel cross sections;

(3) Compute accurate hydrographs at the dam;

(4) Have low sensitivity to parameters that are subject to interpretation or debate; 
(5) Allow the dam structure to discharge water other than through the breach;

(6) Have numerical stability and accuracy;

(7) Simulate flow on hydraulically steep or mild slopes;

(8) Require no data alteration to get the model operational;

(9) Allow for easy redesign and data changes;

(10) Print and plot results in an easily readable format; and

(11) Have simplicity, economy, flexibility, and a minimum number of user steps in a complete simulation.

MATHEMATICAL MODELS

$\underline{\text { MP Model }}$

The modified Puls method is a hydrologic routing technique that is based only on the conservation of mass. The method was originally designed for use in routing flood waves through reservoirs. However, it can also be used to route flood waves in riverine systems, which is one of its uses in the dam-break routing problem. According to Chow (1964) the method requires the use of invariable storage-outflow relationships for each reservoir or stream segment.

The modified Puls method arranges the continuity equation, expressed in finite time intervals, in the following form:

$$
\frac{I_{1}+I_{2}}{2}+\left[\frac{S_{1}}{\Delta t}+\frac{\phi_{1}}{2}\right]-\phi_{1}=\frac{S_{2}}{\Delta t}+\frac{\phi_{2}}{2}
$$

where

$I$ is the inflow rate,

$\varnothing$ is the outflow rate,

$S$ is storage,

and $\Delta t$ is the time interval between time steps 1 and 2 (Soil Conservation Service, 1972).

A so-called working curve of $\phi_{2}$ versus $\left[\frac{S_{2}}{\Delta t}+\frac{\phi_{2}}{2}\right]$ permits a time-sequence solution of equation ${ }^{2}$. The working curve is computed from the time step interval and the storage-outflow table. All terms on the left-hand side of equation 1 are known; therefore, the value of the $\left[\frac{S_{2}}{\Delta t}+\frac{\phi_{2}}{2}\right]$ term and the working curve can be used to compute $\varnothing$ at the new time step. Then the storage-outflow table is used to determine a new storage value. 
The assumptions used in the modified Puls method are: (1) the water surface in the reservoir is level and in the channel its slope corresponds to steady flow conditions, (2) the water surface responds instantaneously to inflows and outflows, (3) outflows are uniquely described as a function of storage, and (4) a time interval is no larger than $2 \times S / \varnothing$. The model's major advantage is simplicity and its major disadvantage is the lack of rigorous mathematical representation of the reservoir-stream system and the flow dynamics.

A very large part of the application of the modified Puls method involves the stage-storage-outflow tables. For the river below the dam, the tables are computed from several water-surface profiles which are first computed by a step-backwater subprogram and several discharges. Tables for the dam in the original and breached condition are supplied by the user as input data.

The equation used for the three field sites evaluated in this report is the dam-break equation for a trapezoidal channel and breach which was presented by Price and others (1977). The equation is

$$
Q_{p k}=\frac{8}{27} \sqrt{g} H^{3 / 2}\left(\frac{2}{5} b+\frac{3}{5} T\right)
$$

where

$\begin{array}{ll}Q_{p k} & \text { is maximum discharge, } \\ g & \text { is acceleration of gravity, } \\ H & \text { is height of initial water level above breach base, } \\ b & \text { is width of breach base, } \\ T & \text { is top width of breach at initial water level. }\end{array}$

The model begins its computation by routing a flood wave through the reservoir using the tables for the dam in the original condition. When the water level rises to a preselected elevation the table representing the dam in the breached condition is used, thus simulating an instantaneous failure. The incoming flood wave is then completely routed through the reservoir with the latter table. Finally, the model begins stepping through the river reach, subreach by subreach, until the downstream end is reached. Each time the flood wave is completely routed through a subreach before moving to the next subreach.

The design of the step-backwater subprogram used in the MP model allows a nonprismatic river reach, with or without inactive flow areas, which may have subcritical or supercritical flow in any subreach and at any discharge. The computations are made in the upstream direction for subcritical flow and in the downstream direction for supercritical flow. Any time the subprogram is unable to solve the equations, it uses the normal depth for that cross section. The method does not explicitly calculate the travel of a flood wave moving through a stream system. 


\section{USTFLO Mode1}

A general purpose unsteady open-channel-flow model originally developed by Garrison and others (1969), and documented by the Corps of Engineers (1977), has been used by Price and others (1977), and Gundlach and Thomas (1977) for simulating dam-break floods. The model is used for dam-break analysis by selecting appropriate designs and options.

The one-dimensional unsteady flow equations used in the development of the USTFLO model follow.

$$
\frac{\partial(A V)}{\partial x}+B \frac{\partial h}{\partial t}-q=0
$$

and

$$
\frac{\partial h}{\partial x}+\frac{V \partial V}{g \partial x}+\frac{\partial V}{g \partial t}+\frac{q}{g A} V=S_{f}
$$

where

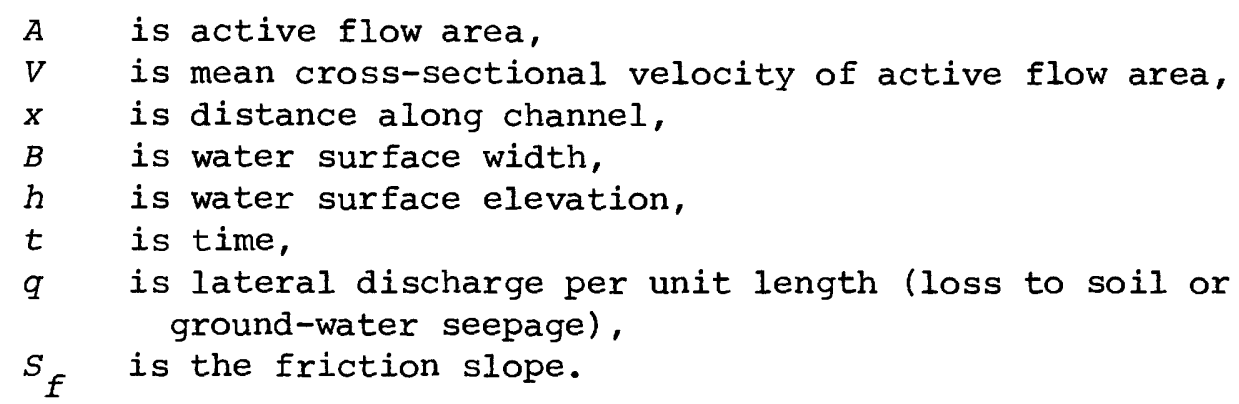

The numerical analysis technique is a leap-frog scheme. It is explicit and has time lines going through alternating odd and even computational nodes. The scheme advances the solution along the time axis where solutions are alternated between the odd and even nodes in the computation net. Only the computed values at the odd nodes are suitable for analysis. The computational nodes must be evenly spaced. For computational stability $\Delta t$ must meet certain criteria which are a function of $\Delta x$ and channel characteristics.

According to Gundlach and Thomas (1977) the characterization of the USTFLO model to reservoir-stream system for dam-break flood wave analysis depends on the type of breach. If the breach is 100 percent of the stream cross-section then the dam is treated as an internal node. If a partial breach is simulated, the reservoir part is simulated in one step and its outflow routed through the channel in another step.

The advantages of using the USTFLO model include (1) good documentation, (2) general familiarity owing to its long-term use and availability, and

(3) flexibility in boundary conditions. Some of the disadvantages, as pointed out by Gundlach and Thomas (1977), are difficulty in establishing initial conditions and tendency for the upstream node to go dry in certain situations, thereby aborting the computer run. The USTFLO model 
documentation states that oscillations are a common problem for very small water-surface slopes, such as in reservoirs. For the tests conducted in this investigation these difficulties prevented successful simulations for the Johnstown and Toccoa Falls data sets; therefore, no results are presented for these two sites.

\section{DBFF Mode1}

The DBFF model has been developed and documented by Fread (1977) of the National Weather Service. The DBFF model is a hydraulic model that solves the complete St. Venant equations of unsteady open-channel flow. It has been developed with the primary purpose of simulating dam-break flood waves; therefore, it has many useful functions that are usually missing in other models. Furthermore, it was designed with an emphasis on real-time flood forecasting. However, for this investigation, it has been slightly modified with an emphasis on general applications. The basic approach and the equations were not changed.

Fread used the conservation form of the two equations in which discharge $(Q)$ and water-surface elevation (h) were the dependent variables. One equation is the conservation of mass (continuity)

$$
\frac{\partial Q}{\partial x}+\frac{\partial\left(A+A_{O}\right)}{\partial t}-q=0
$$

where

$A_{O}$ is the inactive cross-sectional area.

The other equation is the conservation of momentum (motion)

$$
\frac{\partial Q}{\partial t}+\frac{\partial\left(Q^{2} / A\right)}{\partial x}+g A\left(\frac{\partial h}{\partial x}+S_{f}+S_{C e}\right)=0
$$

where

$\begin{array}{ll}S_{f} & \text { is evaluated from the Manning equation for steady uniform flow, } \\ \text { and } S_{c e} & \text { is the expansion-contraction slope, defined by }\end{array}$

$$
S_{c e}=\frac{k}{2 g} \frac{\Delta V^{2}}{\Delta x}
$$

where

$k$ varies from -1 to +1 with the negative values for expansion

$v^{2}$ and positive values for contraction,

and $\Delta V^{2}$ is the difference between the square of the velocities at

two adjacent computational nodes separated by a distance, $\Delta x$.

The $q$ term is assumed to have no velocity component in the $x$-direction. 
The numerical solution is obtained by a nonlinear implicit finitedifference technique. Fread selected the "weighted four-point scheme" which allows unequal distance and time steps and exhibits good stabilityconvergence properties. In this scheme the continuous $x-t$ region, in which the solutions of $h$ and $Q$ are sought, is represented by a rectangular net of discrete points. Fread uses a weighting factor of 0.60 , meaning that the derivatives are written at a point slightly forward of and above a grid's center.

By use of two boundary conditions, discharge at the upstream end and stage-discharge relation for nonuniform, unsteady flow at the downstream end, a system of $2 \mathrm{~N}$ equations and the same number of unknowns result. $N$ denotes the number of nodes in a time line. The resulting system of $2 N$ nonlinear equations with $2 N$ unknowns is solved by a quad-diagonal Gaussian elimination algorithm (Fread, 1971) and a functional interactive procedure, the Newton-Raphson method.

Simulation of a reservoir-stream system with the DBFF model begins by automatically computing the reservoir's outflow hydrograph. The computational method can be either the dynamic formulation described above, which is used in the downstream reaches, or a hydrologic (storagerouting) technique. The latter technique uses the continuity equation which requires a stage-surface area table. The outflow is the sum of the discharges through the outflow structures and the breach. The breach is assumed to start forming when the reservoir's water surface reaches a specified level. The breach initially has its base at the waterline and has a zero bottom width. During the progressive failure, the base broadens and moves downward at a constant rate, as specified by the duration of failure. The discharge through the breach $\left(Q_{b}\right)$ is assumed to be a function of head and the breach's shape. $Q_{b}$ is computed by the broad-crested weir equation. The equation has two components, one for a triangular shape and the other for a rectangular shape. Together they can represent a trapezoidal-shaped breach. If the breach's outflow becomes submerged, a submergence correction factor is automatically computed and used to adjust the outflow.

After computing the complete outflow hydrograph at the dam, the model begins routing it through the stream. If needed, the stream can be divided into segments where the state of flow is always subcritical or supercritical. In such cases the routing is completed for one segment before moving to the next downstream segment.

The advantages of the DBFF model include: (1) reasonable representation of the physical and hydrodynamic aspects of the reservoir-stream system, (2) primarily for dam-break simulations, (3) relatively easy one-step application, and (4) an efficient numerical analysis scheme. However, in some applications, the model will fail when the state of flow changes with stage in a given segment. Also, the model may fail to start if the stream-bed's slope is very irregular or if there are major expansions or contractions. These, and most other problems, can be overcome with slight alterations of data or a slight redesign of the model's characterization of the reach. 
The concept of Chen and Druffel (1977) in coupling the MOC and J879DB (referred to as LIF in their report) models was to use the advantages or strengths of each and at the same time eliminate their weaknesses. The MOC model simulates the flood wave with the complete flow equations and the Rankine-Hugoniot (shock) equations. When the use of the shock equations is considered unimportant, then the more efficient J879DB model is put into operation to perform the remaining computational tasks. The results of the MOC model at the time of linkage are the initial conditions of the J879DB model. This modeling approach treats the dam as an internal node.

The form of the basic flow equations, for example, continuity and motion, used in the MOC and J879DB models, assuming no lateral flow, follows

$$
\frac{\partial A}{\partial t}+\frac{\partial A V}{\partial x}=0
$$

and

$$
\frac{\partial A V}{\partial t}+\frac{\partial\left(\beta A V^{2}\right)}{\partial x}=g A\left(S_{0}-S_{f}\right)-g A \frac{\partial y}{\partial x}
$$

which are subject to the following initial and boundary conditions:

at $t=0$ :

$$
\begin{aligned}
& y(x, 0)=y_{0}(x) \\
& V(x, 0)=V_{0}(x)
\end{aligned}
$$

at $x=0$ :

$$
A(0, t) \quad V(0, t)=Q_{0}(t)
$$

at $x=x_{s}(t)$ :

$$
\begin{aligned}
& \dot{\xi}=\frac{A_{1} V_{1}-A_{2} V_{2}}{A_{1}-A_{2}} \\
& V_{1}=V_{2}-\left(A_{1}-A_{2}\right)\left(\frac{g}{A_{1} A_{2}}\left[\frac{A_{1} \bar{y}_{1}-A_{2} \bar{y}}{A_{1}-A_{2}}\right]\right)^{1 / 2}
\end{aligned}
$$


where

$V \quad$ is the average velocity of flow in the cross-section,

$B$ is the momentum correction factor for the velocity distribution of flows,

$S_{O}$ is the channel slope,

$y$ is the depth of flow,

$x_{S}$ is the location of the shock,

$\dot{\xi}$ is the propogation velocity of the shock,

$A_{I}$ is the conjugate cross-sectional area of the flow on the upstream side of the shock,

$A_{2}$ is the conjugate cross-sectional area of the flow on the downstream

2 side of the shock,

$\bar{y}_{I}$ is the depth to the centroid of $A_{I}$,

$\bar{y}_{2}$ is the depth to the centroid of $A_{2}$ '

$V_{1}$ is the conjugate average velocity of flow on the upstream side of the shock,

and $V_{2}$ is the conjugate average velocity of flow on the downstream side of the shock.

The functions $y_{0}(x), V_{O}(x)$, and $Q_{O}(t)$ are the initial depths, velocities, and discharges, respectively. Equations 13 and 14 are the Rankine-Hugoniot equations and are used only in the MOC model. They serve as a moving downstream boundary. For the J879DB model a rating curve, based on normal flow depths at the downstream end of the reach, serves as the downstream boundary.

The model uses the method of characteristics. It uses an explicit linear scheme based on a specified-time-interval-grid net to solve the velocities and depths terms in the characteristic form of equations 8 and 9.

The numerical analysis technique used by the J879DB discretizes the partial derivatives of equations 8 and 9 , linearizes the equations by representing nonlinear multipliers of the space derivatives at the known time level, and solves the resulting linear algebraic equations implicitly (Keefer, 1976). The finite-difference approximations are based on a six-point grid net, four on the old time line and two on the new time line. If a variable dissipative term is set to zero, the scheme is a four-grid (rectangular) net and fully centered. The dissipative term is used only in selective parts of the reach to achieve stability.

The MOC model was originally developed for the computation of urban storm runoff hydrographs caused by time and spacially-varying rainstorms. The J879DB model originated as a general-purpose streamflow simulation model. Land (1978b) documented the 3879 version of the model, which was formulated by Keefer (1976). The MOC model has undergone extensive modifications to incorporate the shock equations and the dam-break boundary conditions. This includes a scheme of mathematically developing a conveyance tube for the movement of water through the rapid contractionexpansion of a partial breach. The conveyance tube causes the area of a 
cross section in the vicinity of the dam to be divided into storage and conveyance. It reduces the $\partial A / \partial x$ term and thereby increases computational stability and accuracy. The upper limit of the conveyance tube starts at the dam at $t=0$ and moves upstream with time until the upstream end of the reservoir is reached. The lower limit is specified by the user. The J879DB version facilitates the coupling and includes (1) the dissipative term, (2) the means of delineating active and inactive flow areas of a cross-section, and (3) the ability to receive discharges or depths and velocities from the MOC model as initial conditions.

The first step in applying this procedure is to simulate the reservoir and river with the MOC model. The breached dam is an internal node. At the initial time, this node has the reservoir's water level on the upstream side and the river's level on the downstream side, thus a shock front or discontinuity of water surfaces is formed. The MOC model is run until the shock front either traverses the reach or nearly dissipates. At this time the computed velocity and depths or discharges at the last time step are input as initial conditions in the J879DB model. When transferring discharges, a step-backwater subprogram is used to establish the depths at each of the J879DB model's nodes. J879DB is then run until the simulation is completed.

The advantages of the MOC model include almost no restrictions on the shock wave computation and the simulation of subcritical, supercritical, or mixed flow in a nonprismatic channel while the J879DB model includes an efficient computational algorithm and an accurate description of cross-section geometry. Disadvantages of the MOC model include (1) only asymmetric trapezoidal cross-section shapes, (2) small evenly spaced distance increments, (3) small time steps, (4) difficulty with expansion and contractions, including the dam, and (5) relatively expensive computational costs. The J879DB model does not handle large changes in stage with time or space nor states of flow other than subcritical.

Applying this modeling approach to the three field data sets identified several problems. In order to proceed with the model evaluations some alterations to the suggested approach by Chen and Druffel were desirable. The biggest problem stems from the different representations of the geometric shape of the cross sections. When the velocities and depths are transferred, the two models may compute different discharges at this instant of time. If the models use different cross-section thalwegs, then the two water-surface profiles will also be different at this instant. To prevent this problem, the discharges were transferred and a step-backwater program using the conservation of energy principle was used to compute the depths and velocities. This approach could cause a discontinuity in the water-surface elevation hydrographs.

Another problem encountered was the state of flow. The MOC model has difficulty propagating the shock front in subcritical flow while the J879DB will correctly simulate only subcritical flow. However, the supercritical flows computed in the MOC model may be subcritical in J879DB due to the change in a cross section's shape. 
Although the two models are generally numerically stable, some difficulty is encountered in starting J879DB. Much of the problem is caused by the step-backwater program, which assumes steady flow, not computing hydrodynamically stable flow conditions. Also, the MOC model yielded an irregular profile of discharges that had to be smoothed. The combination of factors usually requires a very small time step in the J879DB model. Finally, the approach does not allow either model to "warm-up", thereby eliminating any of the irregularities caused by inaccurate initial conditions.

\section{CHARACTERIZATION OF TEST CASES}

Mathematical model simulations require the characterization of geometry of the reservoir-stream system along with the initial and boundary conditions. Characterization of the stream requires dividing it into discrete subreaches. Characterization of the flood event requires a continuous definition of the hydrologic conditions influencing the simulation. Mathematically representing a test case with a specific model usually requires meeting a rigid set of specifications except in the selection of the node spacing $(\Delta x)$ and possibly the time step $(\Delta t)$. However, some models do allow a variation in design or a selection of options. As a result, there are no set rules in the schematization (grid design) of the reservoir-stream system. Instead the user must rely on experience, experiments and engineering judgment. Selecting the time step is usually dictated by grid design, geometric data and the shape of the hydrograph.

For purposes of this report, the following definitions apply: cross sections refer to the ones obtained by field surveys; computational cross sections are the ones used as primary input to the models; and, computational nodes refer to the locations where discharge and watersurface elevations are computed. Often the cross-section data are expanded or interpolated to yield computational cross sections as needed by a model. A model may use the computational cross sections as computational nodes, or it may compute computational nodes from the computational cross sections.

The largest task of data preparation and handling is the geometric description of the channel. The task requires preserving the detail of the data and providing a means of arranging it into various formats and details as required by the various models. The selected procedure uses a computer program entitled "Geometric Elements from Cross Section Coordinates" (GEDA) available from the Corps of Engineers (1976). This computer program prepares from field survey data tables of hydraulic elements at evenly spaced intervals. This allows the channel geometric data to be coded in detail only once. For various spacings of computational cross sections the GEDA program is simply rerun with different spacing requests. Computer programs were written and used to transform the format of GEDA output into the format required by specific models. Efforts were made to have the models use equivalent data as far as possible, but not to handicap any model with the limits of others. 
Model application necessarily makes some simplification of the prototype and often requires data that cannot be accurately or reasonably measured. Such input requirements for the MP, DBFF, and J879DB models include the designation of a cross section's conveyance area which may or may not differ from the storage (total) area and the selection of a representative Manning $\mathrm{n}$ value as a function of depth. The procedure for determining these original input data was selected by conducting several experimental runs with the MP and DBFF models. Based on comparisons of the computed results with the high-water marks and discharge measurements, the procedure takes the ratio of the estimated velocity in the overbank to the estimated velocity of the main channel and assigns this fraction of the overbank as a conveyance (active flow) area. The remainder of the overbank is a dead-storage (inactive flow) area. For example, for a given stage the estimated velocities are 1 and $10 \mathrm{ft} / \mathrm{s}$ in the overbanks and main channel, respectively. Then one-tenth of the overbanks' crosssectional area plus all of the main channel would be considered active and nine-tenths of the overbank area inactive. This assignment procedure maintains continuity of the flow system. For each cross section a constant Manning $n$ value which represents that of the main channel is used throughout the simulation.

One of the constraints in evaluating the models was to test them without the benefit of calibration. This constraint required the models to use information obtained from field data or best original estimates. Such is the case when simulating a hypothetical dam failure. However, in many test runs a model would fail to run with the original data set. To proceed with the investigation, alterations were made to the original data set, generally to the Manning $n$ value, only to the extent necessary to get the model running. All alterations are noted in the discussion.

\section{Teton Dam}

Since the computer program GEDA is used to generate computational cross-section data for the simulation models, the detail of the channel geometry is defined in this step. For Teton Reservoir, a reach length of $80,000 \mathrm{ft}$ and computational cross-section intervals of 4,000 ft were used, resulting in 20 intervals. For Teton River, a simulated reach length of $48,480 \mathrm{ft}$ and an interval of 2,424 ft were used, again resulting in 20 intervals. Inactive flow areas in the computational cross sections were designated where needed. Off-channel storage was ignored.

\section{MP Model}

The MP model represents the reservoir with two stage-storageoutflow tables, one for prebreach and the other for postbreach conditions. The stage-storage-outflow tables generated for each subreach in Teton River consisted of seven points. The discharge ranged from 900 to $2,500,000 \mathrm{ft}^{3} / \mathrm{s}$. The computational cross-section spacing below the dam was a constant $2,424 \mathrm{ft}$. The time step was one minute. The initial water surface altitude was assumed to be 5,301.6 ft at 10:00 a.m. The model computed the breach to occur at 12:20 p.m., when the simulated water surface rose to 5,301.7 ft. The computed time of the breach occurrence is not significant in this report's analysis. No alterations to the data set were required for a successful simulation. 


\section{USTFLO Model}

The design approach of the USTFLO model to the Teton Dam set was to simulate the reservoir in the first step and to route the computed outflow through the river in the second step. For the reservoir, the downstream boundary was a stage-discharge rating table determined by an equation used by Gundlach and Thomas (1977, p. A-6), for example,

$$
Q=\left(\frac{\left(b+z D_{c}\right)^{3}}{\left(b+2 z D_{c}\right)}\right)^{1 / 2} D_{C}^{3 / 2}
$$

where

$z$ is the side slope of breach, and $D_{c}$ is critical depth.

$D_{\text {}}$ was ${ }^{C}$ assumed to be two-thirds of the total depth. A computational space interval of $4,000 \mathrm{ft}$ and a time interval of $2 \mathrm{~s}$ were used. The initial time is 12 noon. The breach occurs instantaneously and at $t=0$.

The model's representation of the river was with computational node spacing of 2,424 ft and a time step of $5 \mathrm{~s}$. Using initial conditions generated by an independent step-backwater program the model was used without any data alterations or special procedures.

\section{DBFF Model}

The dynamic routing option was selected to represent the Teton Reservoir. This approach was considered more desirable since the reservoir was over $15 \mathrm{mi}$ long and rather narrow. The reservoir's geometry was described by 21 computational nodes, equivalent to the computational cross sections generated by GEDA. Using the computations of Gundlach and Thomas (1977) as a guide, the breach was assumed to develop steadily for one hour. As in the MP model, the initial water-surface altitude at the dam was assumed to be 5,301.6 ft at 10:00 a.m. The breach began to develop at 12:06 p.m., when the water level rose to 5,301.7 ft. Again, the computed time of the breach is not important. The time step, selected by the model, ranged from 3.0 to 4.9 minutes.

Along Teton River initial runs of the model were unsuccessful without the use of the expansion-contraction coefficient and extra computational nodes. In the vicinity of the canyon exit into the valley the expansion-contraction coefficient was set at or near maximum allowable values. The required node spacing in the canyon was $1,212 \mathrm{ft}$ and $808 \mathrm{ft}$ in the valley. The time interval ranged from 3.0 to 5.4 minutes.

MOC-J879DB Models

The reservoir-stream system, as simulated by the MOC-J879DB models, uses the dam as an internal node; therefore, separate reservoir and stream simulations are not made. 
Schematizing the site with the MOC model was done with a computational node spacing of 4,000 ft throughout. Special runs of the GEDA program were made to develop the trapezoidal-shaped cross sections. Channel volume balances were made near peak stage conditions. The conveyance tube carrying the discharge through the breach was assumed to extend $10,000 \mathrm{ft}$ below the dam. The MOC model was run for a simulation time of 10 min before linking with J879DB. During this time the time step ranged from 30 to $60 \mathrm{~s}$.

Representation of the Teton site with the J879DB model was with computational nodes spaced at 4,000 ft intervals in the reservoir and 4,848 $\mathrm{ft}$ in the river. Measures taken to get the model operational were to (1) increase the Manning $n$ values up to 40 percent at and immediately below the dam and up to 20 percent in the valley, (2) designate inactive flow areas in the vicinity of the dam, (3) increase the base flow from 960 to $50,000 \mathrm{ft}^{3} / \mathrm{s}$, (4) decrease node spacing to $1,212 \mathrm{ft}$ near the mouth of the canyon and in the valley, and (5) use a $5 \mathrm{~s}$ time step.

\section{Johnstown}

The detail of channel geometry data for modeling purposes was subdivided into 20 subreaches for the stream. In the 13,400-ft reach below the dam these intervals produced twenty-four 558-ft subreaches. The cross-sectional area of all the cross sections was assumed to be active; therefore, no inactive flow areas were designated. Stagestorage and stage-outflow curves for prebreached conditions were provided by J. T. Armbruster (written commun., 1977). Variable tributary inflow entered Laurel Run at two points, 1,180 and 9,650 ft below the dam.

\section{MP Model}

Development of the stage-storage-outflow tables for Laurel Run Reservoir required the consideration of the spillway structures and flow over the dam's eroded crest. The prebreached tables were taken from available curves. The outflow in the postbreach tables included the discharge through the breach (eq. 2) plus the other discharges. Tables for Laurel Run were developed from seven discharges, ranging from 100 to $100,000 \mathrm{ft}^{3} / \mathrm{s}$. The subreach length was $558 \mathrm{ft}$, unchanged from the GEDA output. The time step was $30 \mathrm{~s}$. For modeling purposes the initial water-surface elevation was assumed to be 1,432 ft at midnight on July 19. The breach occurred when the water surface rose to $1,437.2 \mathrm{ft}$ elevation, 2:00 a.m. on July 20. Again, the computed time of the breach is unimportant. No alterations to the data set were required.

DBFF Mode1

The hydrologic routing option was selected in the DBFF model to represent the reservoir. The spillway structure's discharge was represented by a gate with its center at $1,430.0 \mathrm{ft}$ elevation. Flow over the dam 
was represented by uncontrolled flow over a weir. The coefficients were adjusted to produce a stage-outflow rating that reasonably approximated the ones provided by J. T. Armbruster (written commun., 1977). The duration of the breach development was assumed to be $15 \mathrm{~min}$. The DBFF model used the 25 computational cross sections provided by GEDA for computational nodes. The simulation time began at midnight with a water-surface elevation in the reservoir of $1,432.0 \mathrm{ft}$. The simulated dam failure began at 2:06 a.m. Time steps ranged from $45 \mathrm{~s}$ to $15 \mathrm{~min}$.

Data and model simulations indicated that supercritical flow existed in two segments of the reach. Results of the DBFF model indicated that the state of flow changed with flow rates; therefore, to operate the model it was decided to increase the Manning $n$ values in these segments sufficiently to maintain subcritical flow. Where needed, the increase was approximately 20 percent but with a maximum of 50 percent. These two segments could have been simulated as having supercritical flow. Smaller adjustments to the Manning $n$ values would result.

MOC-J879DB Models

The reservoir-stream system was represented by the MOC model with computational nodes every $93 \mathrm{ft}$. The net was made six times finer to reduce the numerical errors. The time step ranged from 7 to $10 \mathrm{~s}$. The conveyance tube through the dam extended to $1,700 \mathrm{ft}$ below the dam. Owing to the rather short study reach and to the relatively steep slopes, the shock front traversed the reach before a linkage with J879DB could be made. However, linkage was made after $10 \mathrm{~min}$ of simulation time to test the coupling approach and the J879DB model, and to complete the flood-wave routing.

The system was represented by the J879DB model with computational nodes at the GEDA-provided computational cross sections except in the reservoir where the spacing ranged from 180 to $547 \mathrm{ft}$. Inside the reservoir, observed cross sections were used in place of the GEDAgenerated data. In order to get the model operational, some Manning $n$ values were increased up to 20 percent, except in the vicinity of the dam where a 100 percent increase was necessary. Also, inactive flow areas were designated for the computational nodes in the vicinity of the dam. A time step of $15 \mathrm{~s}$ was required to start the model.

\section{Toccoa Falls}

The characteristic of the channel geometry, particularly the irregular streambed profile, suggested more detail would be needed between the dam and the falls and less detail below Georgia, Highway 17. The selected computational cross-section detail was 260-, 425-, and 670ft spacings in the upper, middle, and lower segments, respectively. The total number of GEDA-generated cross sections for the stream was 47 . Inside the reservoir the computational cross sections were spaced at 480-ft intervals. Most of the cross sections along the stream required the delineation of active and inactive flow areas. For modeling purposes, an assumed prebreach stage-outflow rating produced $120 \mathrm{ft}^{3} / \mathrm{s}$ at a water-surface altitude of $1,137.0 \mathrm{ft}$. Also, for modeling purposes, the 
vertical effects of Toccoa Falls were assumed to be eliminated by subtracting $175 \mathrm{ft}$ from the elevations above the falls. This adjustment permits the models to represent the creek as if the falls were not there. The elevations reflecting the datum adjustment will be referred to as model elevations.

MP Model

The Toccoa Falls setting was represented by the computational cross sections generated by GEDA and the assumed prebreach and computed postbreach stage-storage-outflow rating tables. The development of the tables for the stream subreaches was made with seven discharges, ranging from 100 to $50,000 \mathrm{ft}^{3} / \mathrm{s}$. The simulation began at midnight on Nov. 5, 1977 with a model reservoir altitude of $962.0 \mathrm{ft}$. The simulation had the dam breaching at 1:09 a.m., when the water surface rose to the model reservoir altitude of $962.5 \mathrm{ft}$. A time step interval of $10 \mathrm{~s}$ was used.

DBFF Model

Representation of Toccoa Creek with the DBFF model required identifying the segments where subcritical and supercritical flow dominated. By use of test model runs and the streambed slope as guides, the stream segments of 0 to $1,040,1,040$ to $2,600,2,600$ to $3,875,3,875$ to $22,800 \mathrm{ft}$ were identified as supercritical, subcritical, supercritical, and subcritical, respectively. Only the GEDA-generated cross sections were needed for computational nodes. However, some Manning $n$ values were adjusted, generally less than 20 percent, to maintain a given state of flow in some segments. An elevation-smoothing option in the model was also needed for convergence at low flows.

The hydrologic routing option was used to generate the reservoir's hydrograph. As in the MP model test, the simulation began at midnight with the assumed reservoir water surface at model altitude $962.0 \mathrm{ft}$. The simulated dam began to breach at 1:06 a.m. when the water level rose to model altitude $962.5 \mathrm{ft}$. The development of the breach was assumed to take $15 \mathrm{~min}$.

$$
\text { MOC-J879DB Models }
$$

The Toccoa Falls system was represented by the MOC model with computational nodes at $200 \mathrm{ft}$ intervals. The time step ranged from 8 to $15 \mathrm{~s}$. The conveyance tube extended below the dam for a distance of 260 ft. The linkage with the J879DB model was made after five min of simulation time.

The geometric channel representation by J879DB was with the GEDAgenerated cross sections. However, considerable data alterations were required to start this model. First, the Manning $n$ values had to be increased in the supercritical-flow segments to get subcritical flow, as required by the model. These increases were often in the 100 percent 
range. Next, inactive flow areas were designated, with some exaggeration, for the computation cross sections in the reservoir and immediately below the dam. Finally, the time step was reduced to five seconds.

RESULTS

From the standpoint of flood mapping, flood crests are the most important result of a dam-break flood-wave analysis. This determines the flooded area and the flood depths. Another important result would be the traveltime of the flood wave. This time represents the available warning time for an actual emergency. For purposes of this report, the computed traveltime is defined as the difference in time between occurrence of the mean of the base and peak discharges for the rising limb of the computed hydrographs at two stream locations. Finally, if velocities are wanted, then discharges are needed.

To aid in the evaluation of a model's results, mass-balance errors were computed for the DBFF and the MOC-J879DB models. These errors should be near zero for the MP model since it is based on a continuity formulation. The USTFLO model did not provide the necessary information. For comparison purposes in this report, the mass-balance errors are given in terms of average rate of mass change (volume change divided by the duration of the simulation) instead of the usual percent error. This way of comparing the exrors is considered to be more definitive since the large volume of water in the reservoir is considered in one model (MOC-J879DB) and not in another (DBFF). Also, the models operated for different lengths of time.

In this report the stream station numbering system originates at the dam, is in hundreds of feet, and is positive in the downstream direction and negative in the upstream direction. For example, station $250+00$ is $25,000 \mathrm{ft}$ downstream of the dam.

\section{Teton Dam}

\section{Discharges}

Two peak discharges were determined by indirect discharge measurements in the study area of Teton River. The discharges were 2.3 million and 1.06 million $\mathrm{ft}^{3} / \mathrm{s}$ at stations $132+00$ and $465+00$, respectively (Ray and Kjelstrom, 1978). Computations made by Gundlach and Thomas (1977), using the USTFLO model and an observed reservoir water-surface hydrograph, yield a maximum breach discharge of $1.8 \mathrm{million} \mathrm{ft}^{3} / \mathrm{s}$. In this study the MP and DBFF models computed less discharge at these three locations, whereas the USTFLO, used without the observed reservoir water-surface hydrograph, and MOC-J879DB computed more. For the measurement at station $132+00$ the computed discharges were $1.0,1.1,2.9$, and $3.6 \mathrm{million} \mathrm{ft}^{3} / \mathrm{s}$ for the DBFF, MP, USTFLO, and MOC-J879DB models, respectively. For the measurement at station $465+00$ the computed discharges were $0.45,0.60$, 1.1 , and $1.4 \mathrm{million} \mathrm{ft}^{3} / \mathrm{s}$ for the DBFF, MP, MOC-J879DB, and USTFLO models, respectively. These measured data and the graphs of the computed peak discharges along the reach are shown in figure 4. As illustrated, 


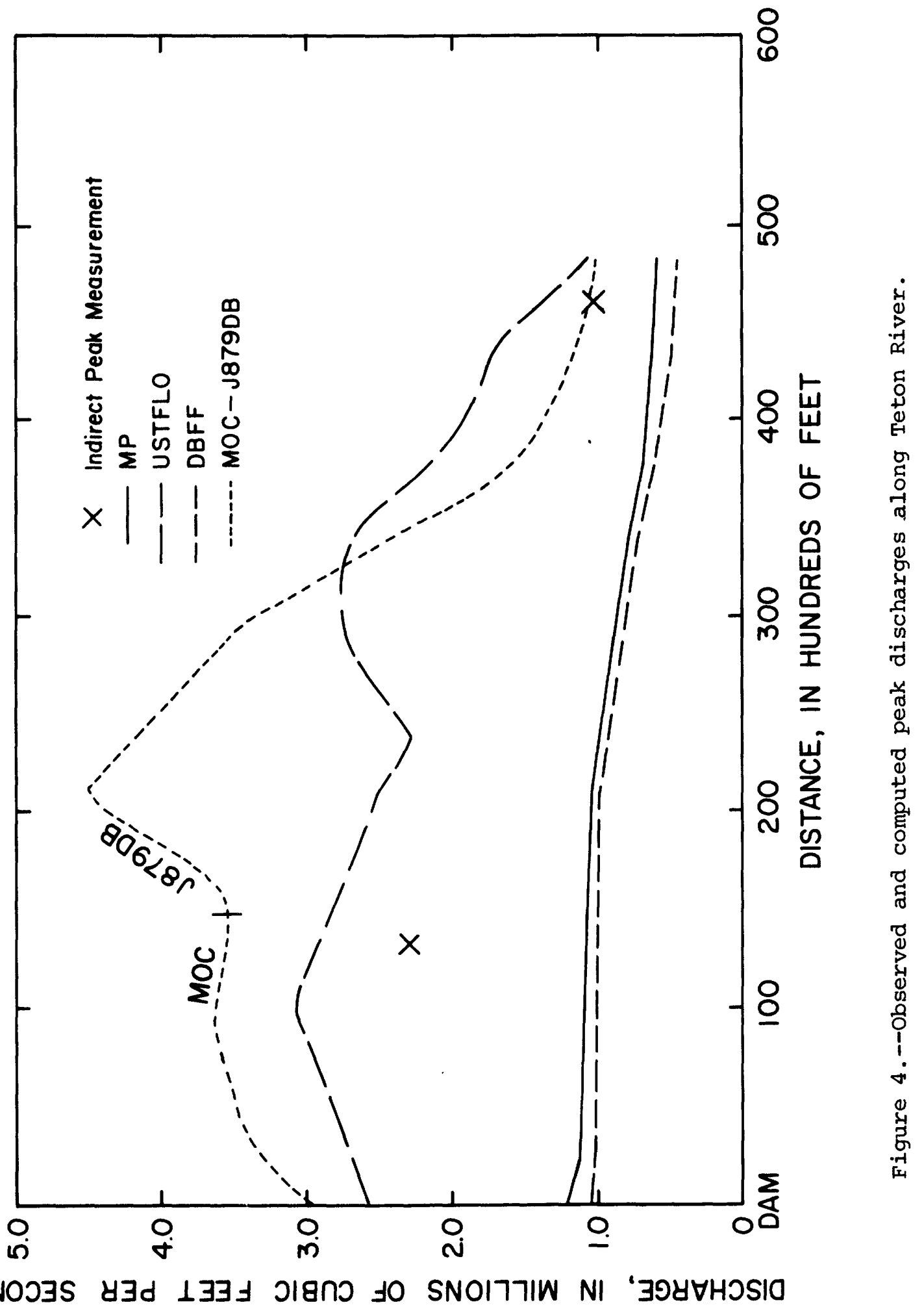


increases in peak discharge in the downstream direction are computed by the USTFLO and MOC-J879DB models. For the USTFLO model, the first increase is probably caused by the model's inability to handle the 2.6 million $\mathrm{ft}^{3} / \mathrm{s}$ surge and the second increase is probably caused by the expansion of the channel. For the MOC-J879DB the first increase is caused by the MOC model's difficulty with the contraction and expansion at the dam and the second increase is the model's adjustment and instabilit: caused by errors in the initial conditions for the start of the J879DB model's simulation. The low peak discharges for the MP and DBFF models may be caused by the outflow equation not representing the flow and boundary conditions.

Although there are no observed discharge hydrographs to compare with the computed discharge hydrographs, it is interesting to compare the computed hydrographs with each other and to see whether they are reasonable. For this purpose discharge hydrographs are shown in figure 5 for stations $0+00$, at the dam, 266+40, in the upper limits of the valley, and $484+80$, at the end of the study reach. The irregular hydrographs at stations $0+00$ and $266+40$ show that the USTFLO and MOC-J879DB models have some stability problems with this test case. The mass-balance errors for the MOC-J879DB model were large, for example, 220,000 and $-146,000 \mathrm{ft}^{3} / \mathrm{s}$ for the MOC and J879DB models, respectively. The DBFF model numerically added water at the rate of $5,500 \mathrm{ft}^{3} / \mathrm{s}$.

The dominant characteristic is the contrast of peak discharges between the USTFLO and MOC-J879DB models and the MP and DBFF models, the former being much larger than the latter. On the basis of very limited observed data the first group appears too large and the second too small.

\section{Flood Profile}

A comparison of the computed flood profiles with the observed highwater marks is made graphically in figure 6 . The most obvious result is the flood profile computed by the MOC-J879DB being irregular and too high. Often its depths were 2 or more times too large. The first rise occurs at the surge front and at the time of coupling. The last two are in the vicinity of the channel's major expansion. Data alterations for the J879DB model probably caused the profile to be somewhat higher. The depths from the USTFLO model were generally too high although there is reasonable agreement. The MP and DBFF models' flood profile have very similar patterns, generally 25 percent too low in the canyon and 25 to 50 percent too high in the valley.

\section{Traveltime}

The flood-wave traveltime from the dam to the valley and from the dam to the end of the study was determined from the hydrographs in figure 5. The first segment is about $5 \mathrm{mi}$ long and the entire reach about $9 \mathrm{mi}$ long. For the first segment the USTFLO and DBFF models 


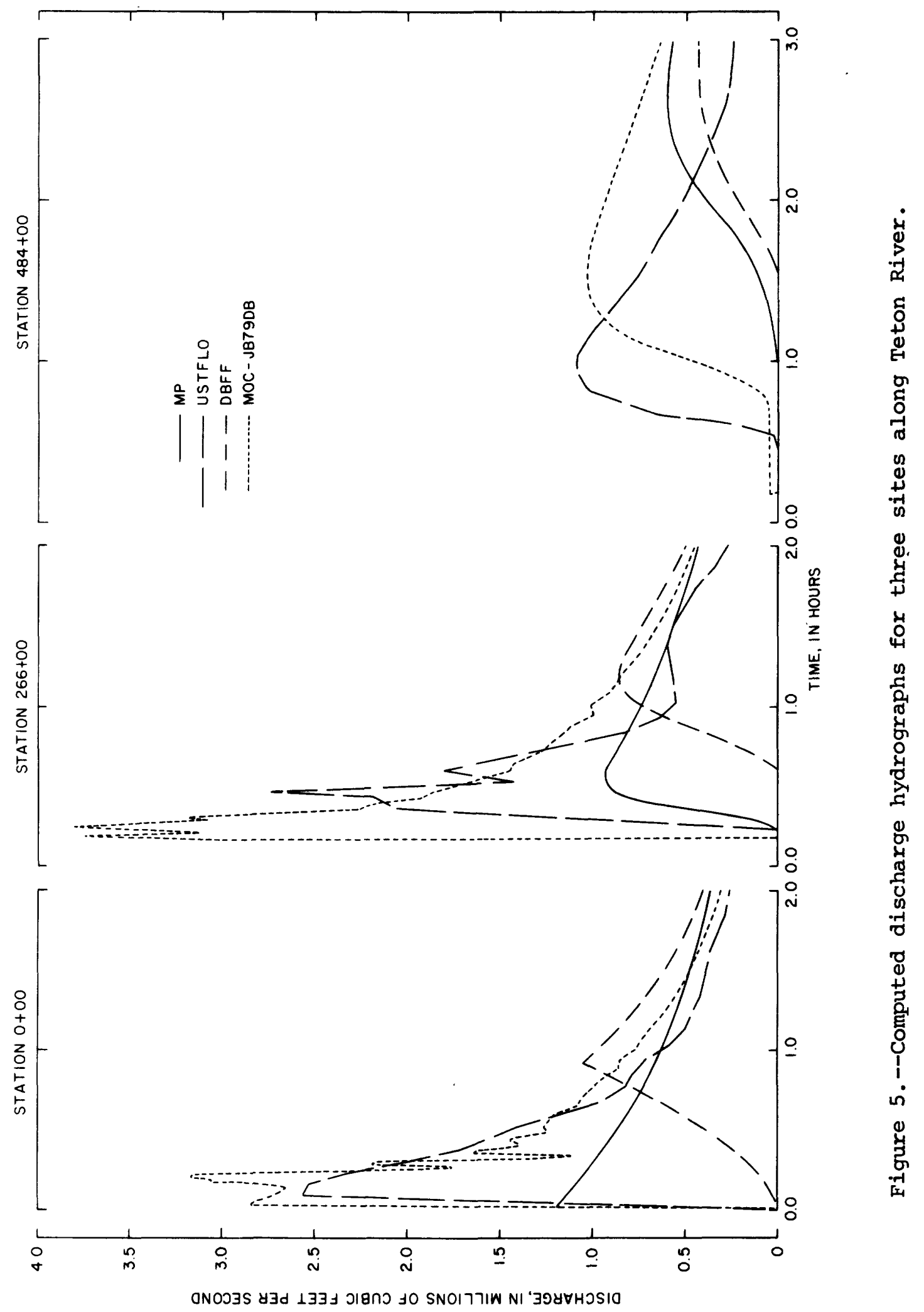




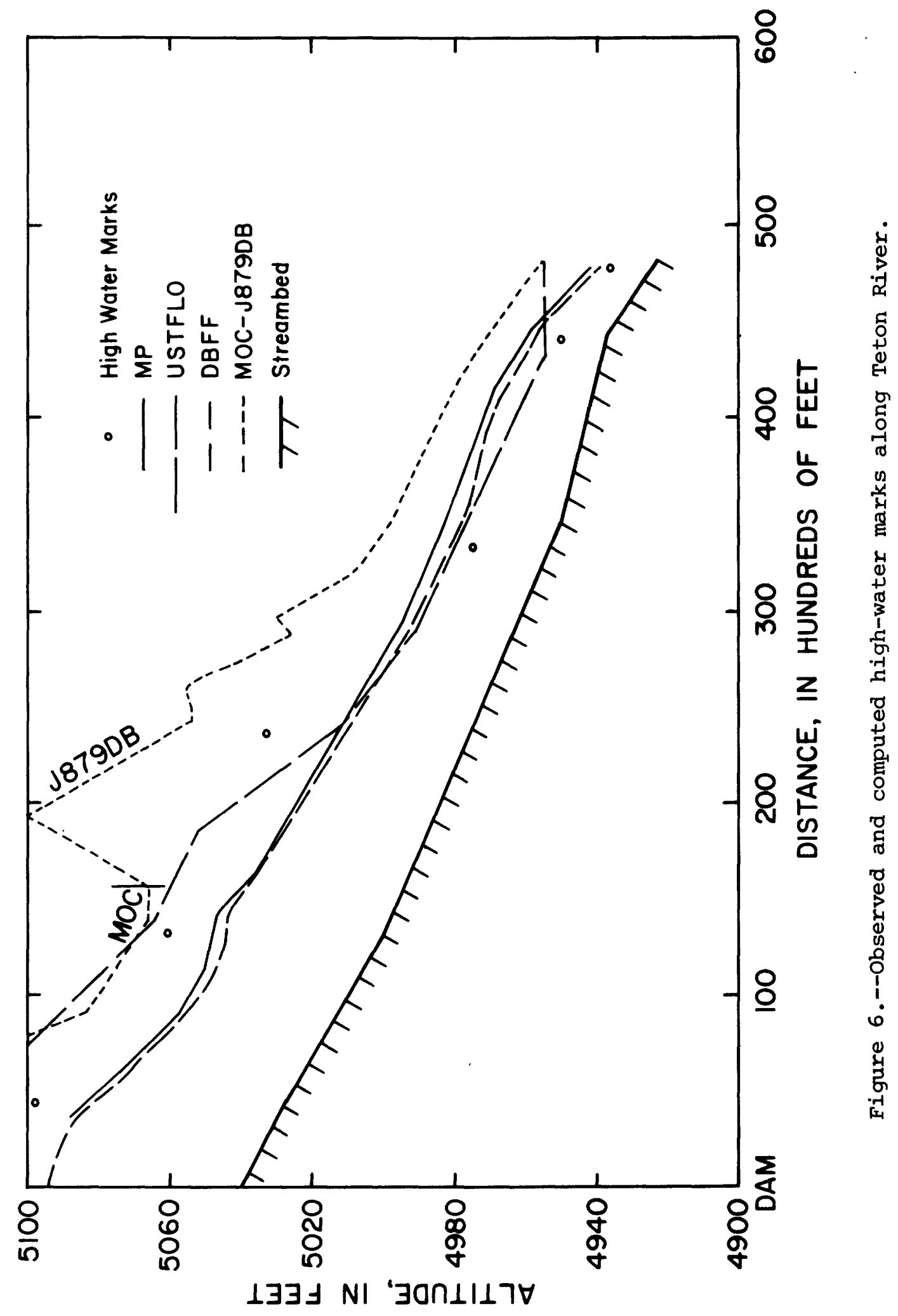


produced similar results, 0.27 and 0.29 hours, respectively. The MOCJ879DB was less, 0.15 hours, and the MP model more, 0.36 hours. For the entire reach the traveltimes were $1.94,0.61,1.60$, and 1.02 hours for the MP, USTFLO, DBFF, and MOC-J879DB, respectively. No observed data are available to determine which model was the most accurate.

\section{Johnstown}

\section{Discharges}

Only one peak discharge measurement is available for Laurel Run, about $1 \mathrm{mi}$ below the dam. The indirectly determined discharge is 37,000 $\mathrm{ft}^{3} / \mathrm{s}$. The computed peak discharges at the same location were 35,000 , 41,000 , and $50,000 \mathrm{ft}^{3} / \mathrm{s}$ for the MP, DBFF, and MOC-J879DB models, respectively. These peak discharges along Laurel Run are shown graphically in figure 7. The peak discharge profiles generally parallel each other with the MOC-J879DB being the highest and the MP being the lowest. A comparison of the computed discharge hydrographs at the dam, in the middle, and the end of the study reach can be made in figure 8 . The only computational irregularities were made by the MOC-J879DB model. It computed an increase in peak discharge immediately below the dam and the fluctuations near the peak of the discharge hydrograph at the dam. Most likely, the cause relates to the MOC model's difficulty with the contraction and expansion at the dam. The results of the mass-balance errors show that water was numerically added at the rate of $643,-10,300$, and $-1,790$ $\mathrm{ft}^{3} / \mathrm{s}$ for the DBFF, MOC, and J879DB models, respectively.

\section{Flood Profile}

A comparison of the computed flood-stage profiles can be made with the observed high-water marks in figures 9 and 10 . In all cases the computed profiles showed good agreement with each other. At most locations they were within $2 \mathrm{ft}$ of each other and only rarely more than $4 \mathrm{ft}$ apart.

Generally there is also good agreement, about $2 \mathrm{ft}$ or less, with the observed high-water marks, except in the stream segment between stations $40+00$ and $60+00$ and near the end of the reach. Overall, the DBFF model appears slightly the highest and the MOC-J879DB slightly the lowest, indicating the MP results give the best agreement. In the DBFF model, increasing the Manning $n$ values in the segments having supercritical flow at high stages to mathematically get subcritical flow at all times contributed to the excess depths. These results probably would have been better if these segments had been simulated as always having supercritical flow.

\section{Traveltime}

Traveltimes were computed to the center of the reach, station $67+00$ and to the end of the reach, station $134+00$. In the first segment, the traveltimes were $0.08,0.09$, and 0.08 hours for the MP, DBFF, and MOCJ879DB models, respectively. For the total reach they were $0.18,0.15$, and 0.14 hours, respectively. 


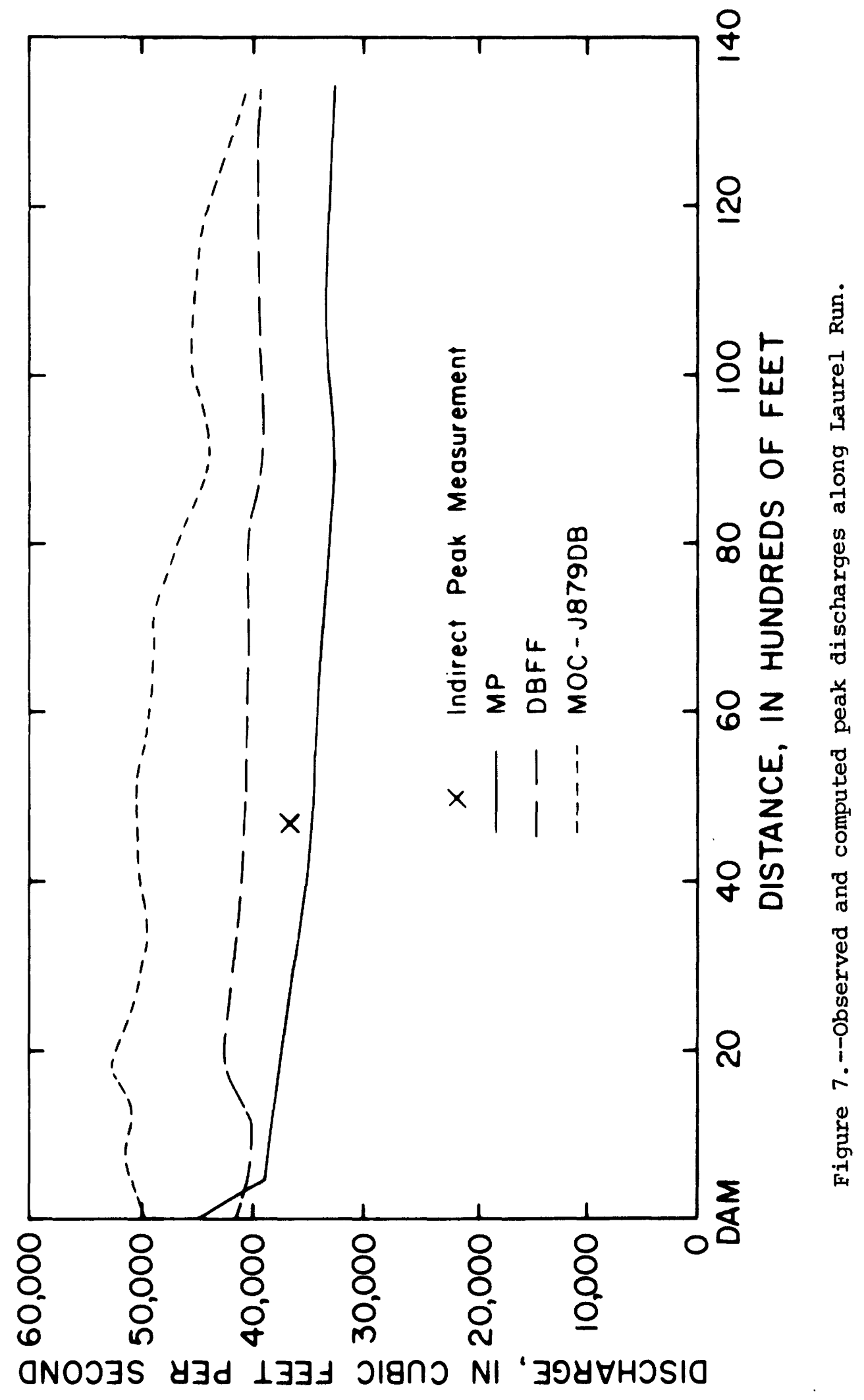




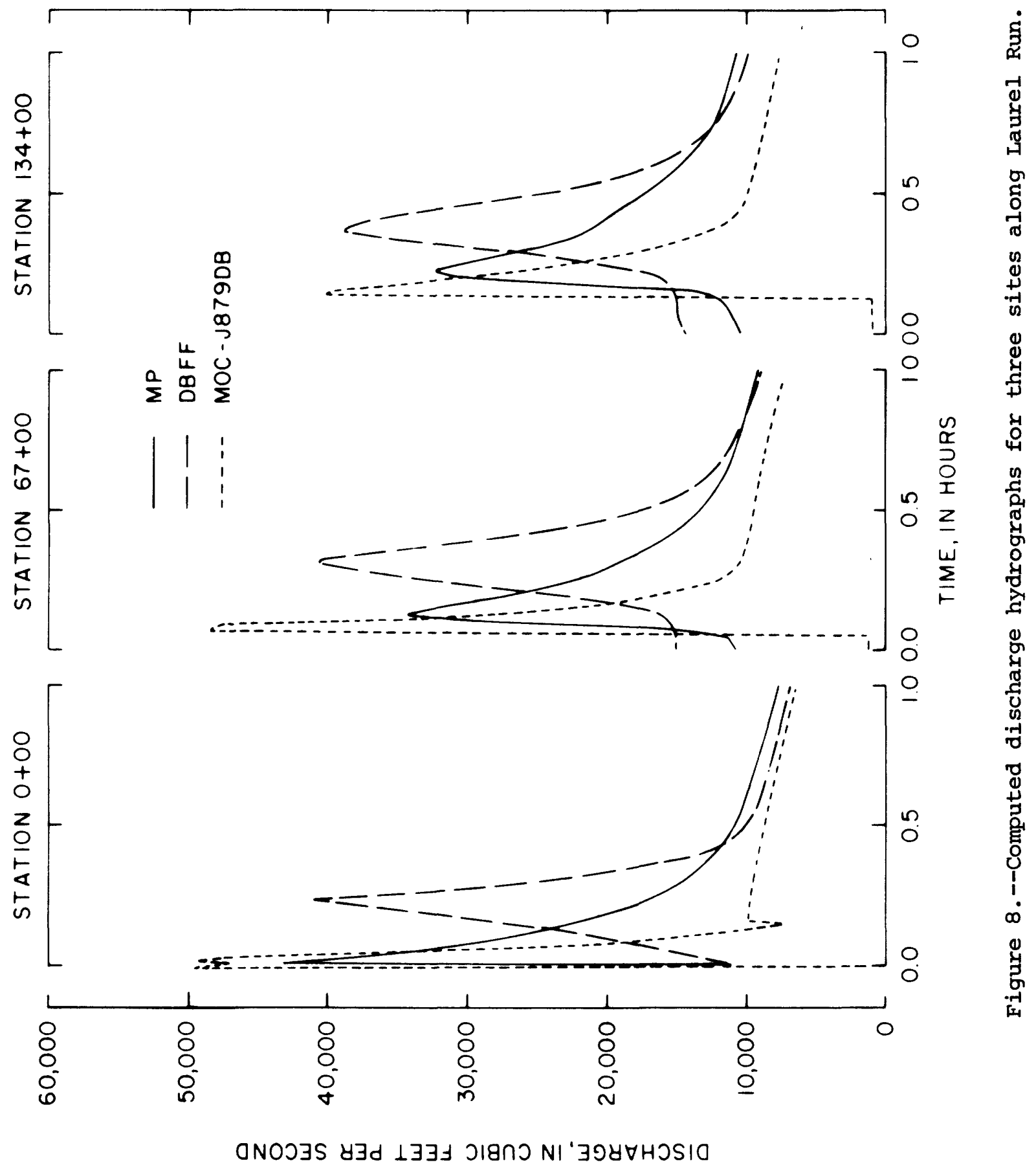




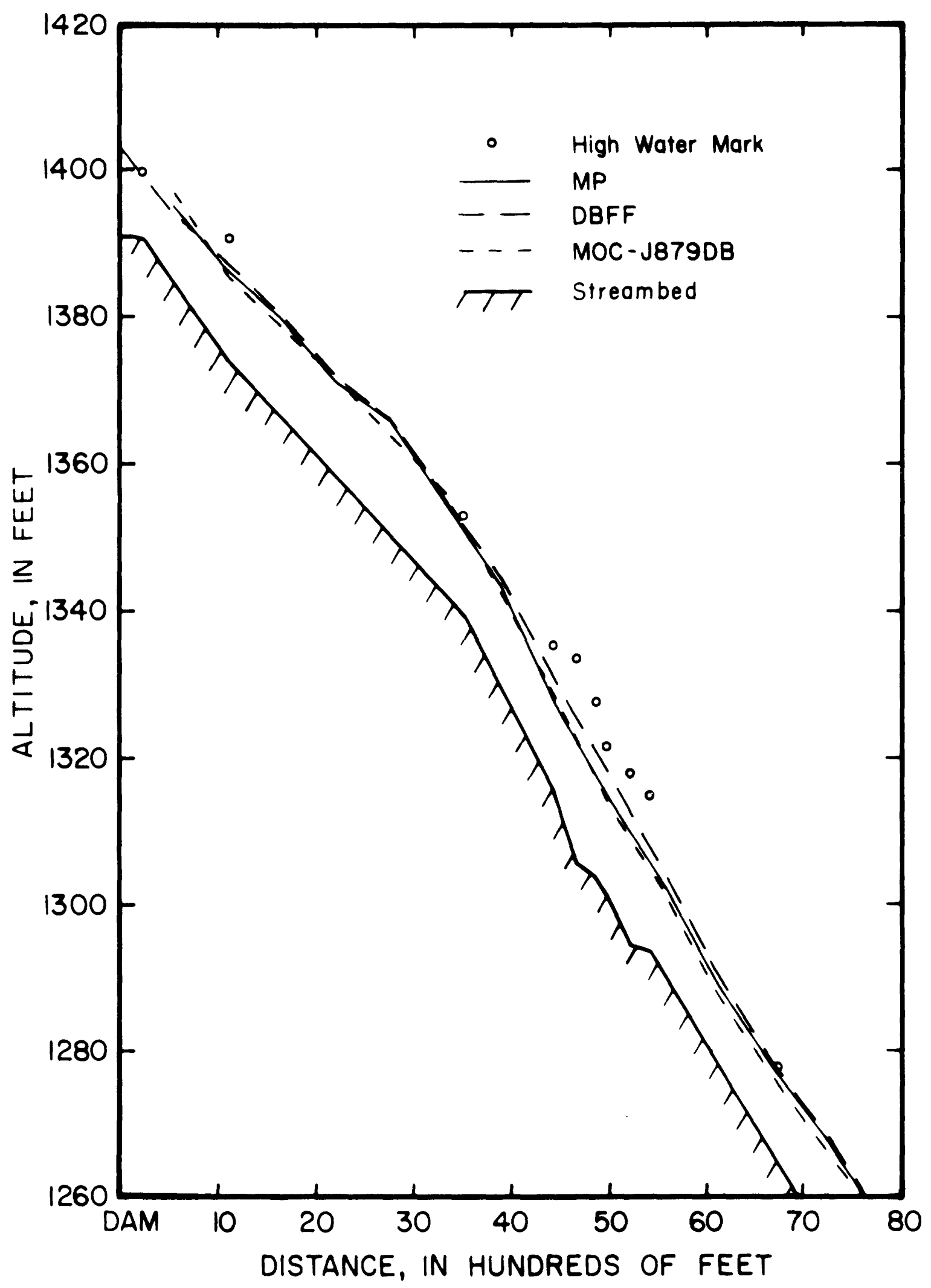

Figure 9.--Observed high-water marks and computed crests for the upper part of Laurel Run. 


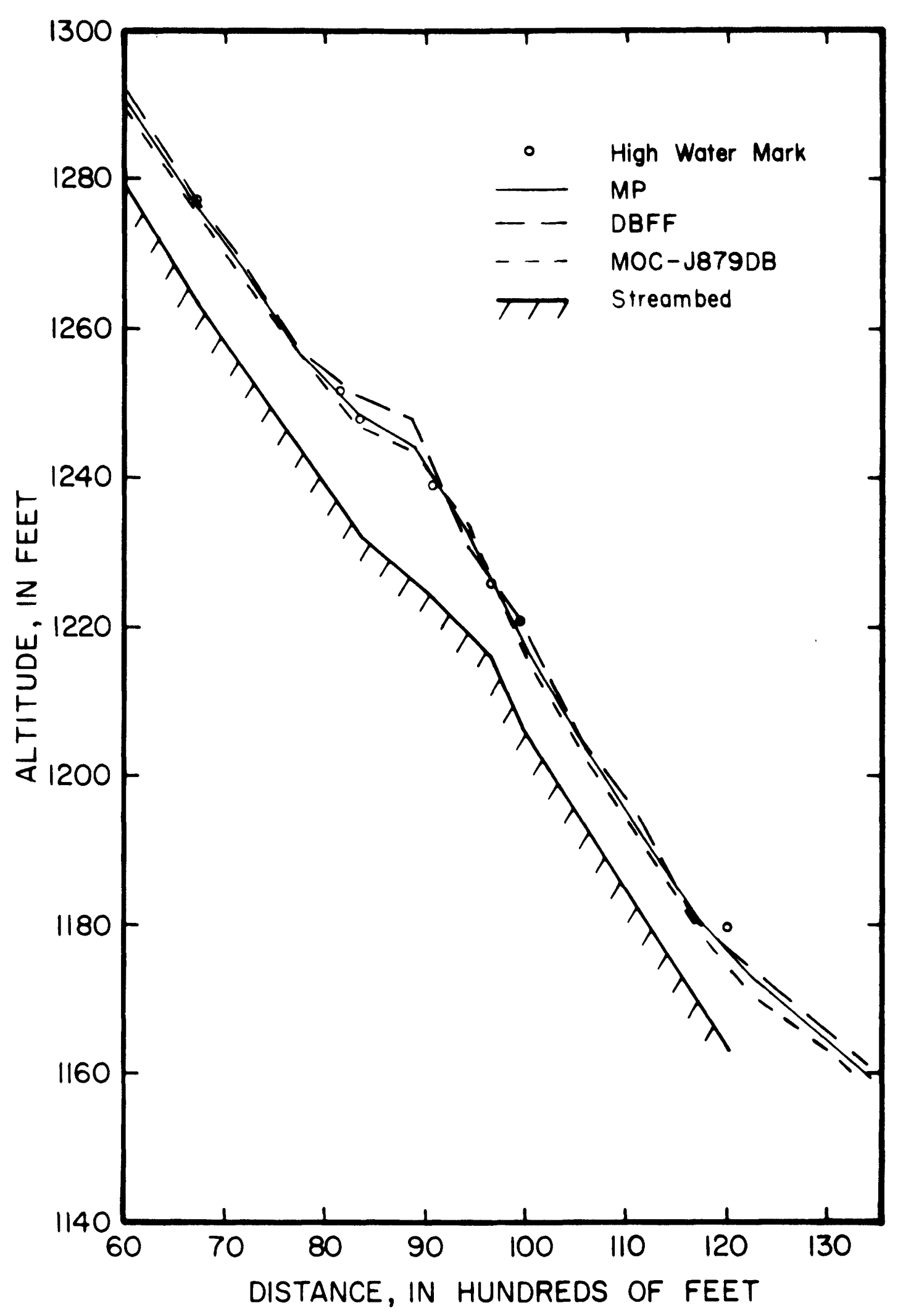

Figure 10.--Observed high-water marks and computed crests for the lower part of Laurel Run. 


\section{Toccoa Falls}

\section{Discharges}

The Toccoa Falls data set is the most extensive and detailed of the three. There are four peak-discharge measurements that can be used to evaluate a model's accuracy. The discharges are 23,000, 24,000, 14,300, and $6,380 \mathrm{ft}^{3} / \mathrm{s}$ at stations $11+00,42+70,108+70$, and $238+70$, respectively. These data along with the computed peak discharges along the stream are shown in figure 11. In the stream segment between stations $0+00$ and $70+00$ the MP model gives the best agreement. However, the MP model gives the poorest agreement in the other segment. The MOC-J879DB computed considerably excessive values in the upper segment but the most accurate values in the lower segment. The DBFF is most consistent, about 20 percent too high throughout the reach. Computed discharge hydrographs at stations $0+00$, at the dam, 72+75, in the first flood plain, and $228+00$, at the end of the reach are shown in figure 12 .

The peak-discharge profile again shows evidence of instabilities and difficulties that the MOC model has immediately below the dam. In this case it computed subcritical flow in this segment, which gives it additional difficulties, whereas the other models computed supercritical flow. The rapid decline in the peak discharges between stations $35+00$ and $80+00$ for the MOC-J879DB model is at least partly caused by the large increase in the roughness used by the J879DB model.

The mass-balance computations show that water was numerically added at the rates of $15,18,500$, and $-950 \mathrm{ft}^{3} / \mathrm{s}$ for the DBFF, MOC, and J879DB models, respectively.

\section{Flood Profile}

Considerable error was expected for the computed flood profile because of trash jams and eroded channels. However, the results are consistently good below station $60+00$ as shown in figures 13 and 14 where the results are generally within $2 \mathrm{ft}$ of the observed values and show no pattern of being too high or low. An exception is below station $200+00$ where the self-setting downstream boundaries caused the computed stages to be too high. In practice, the downstream boundary of the model should be extended past the end of the study reach. With regard to the upper segment, station $0+00$ to $60+00$, the computed flood profile was slightly high with the MOC-J879DB being consistently and sometimes more than $10 \mathrm{ft}$ high. This is at least partly caused by the MOC model computing too much discharge.

\section{Traveltime}

For purpose of comparison the traveltimes were computed from the dam to station $72+75$ and from the dam to the end of the reach. In the first segment the traveltimes were $0.18,0.13$, and 0.14 hours for the $M P, D B F F$, and MOC-J879DB models, respectively. In the entire reach the traveltimes were $0.92,0.74$, and 0.83 hours, respectively. 


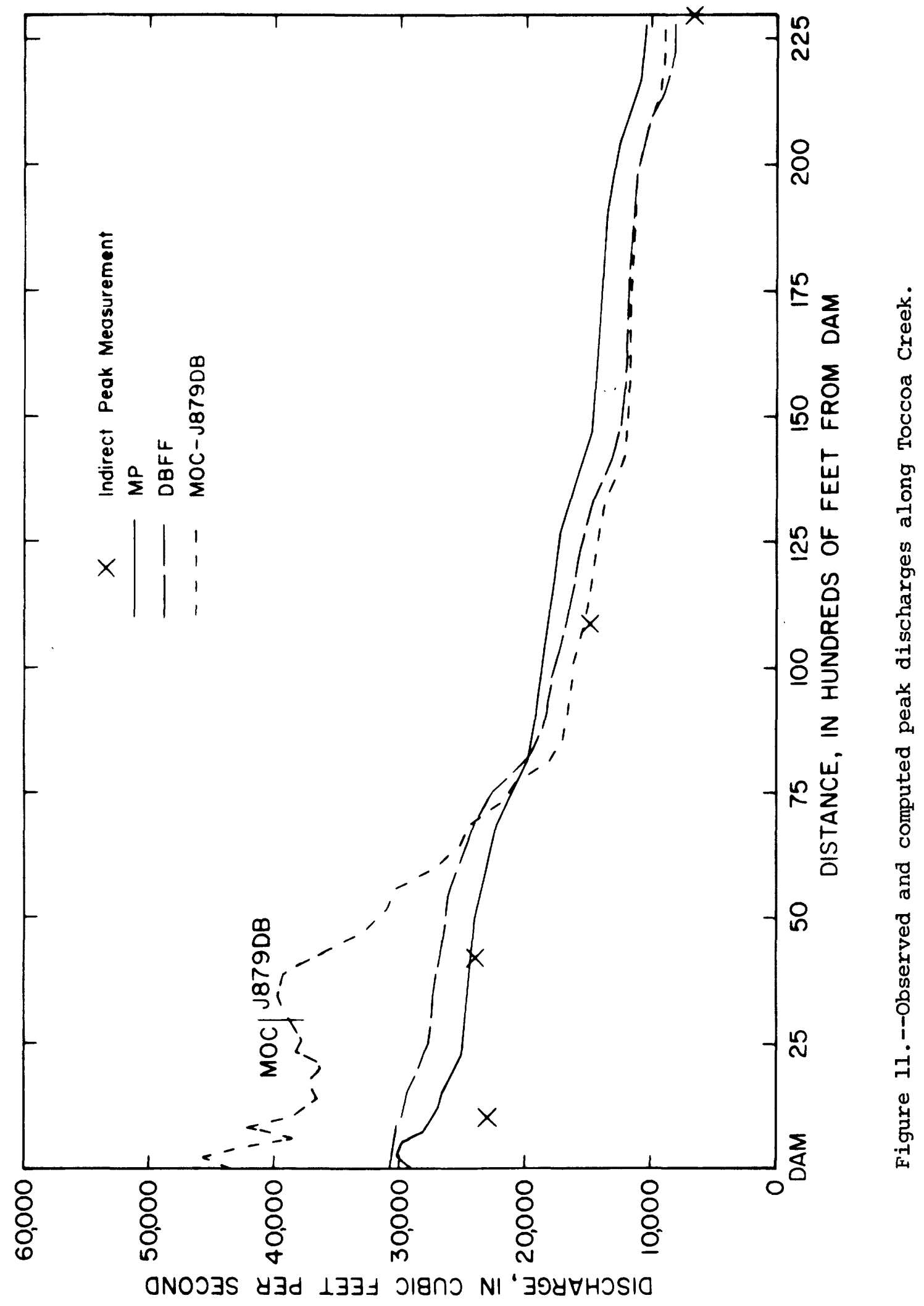




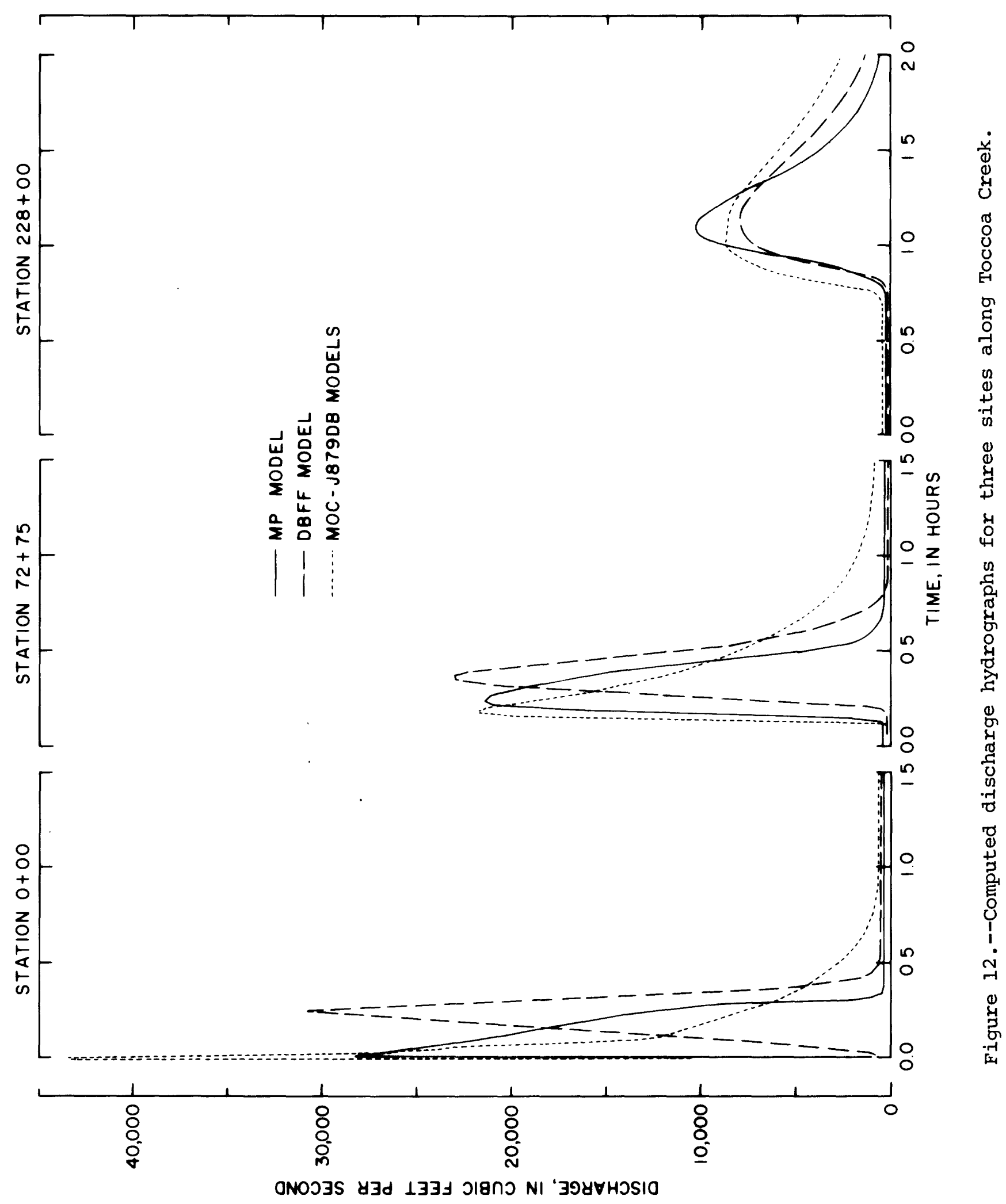




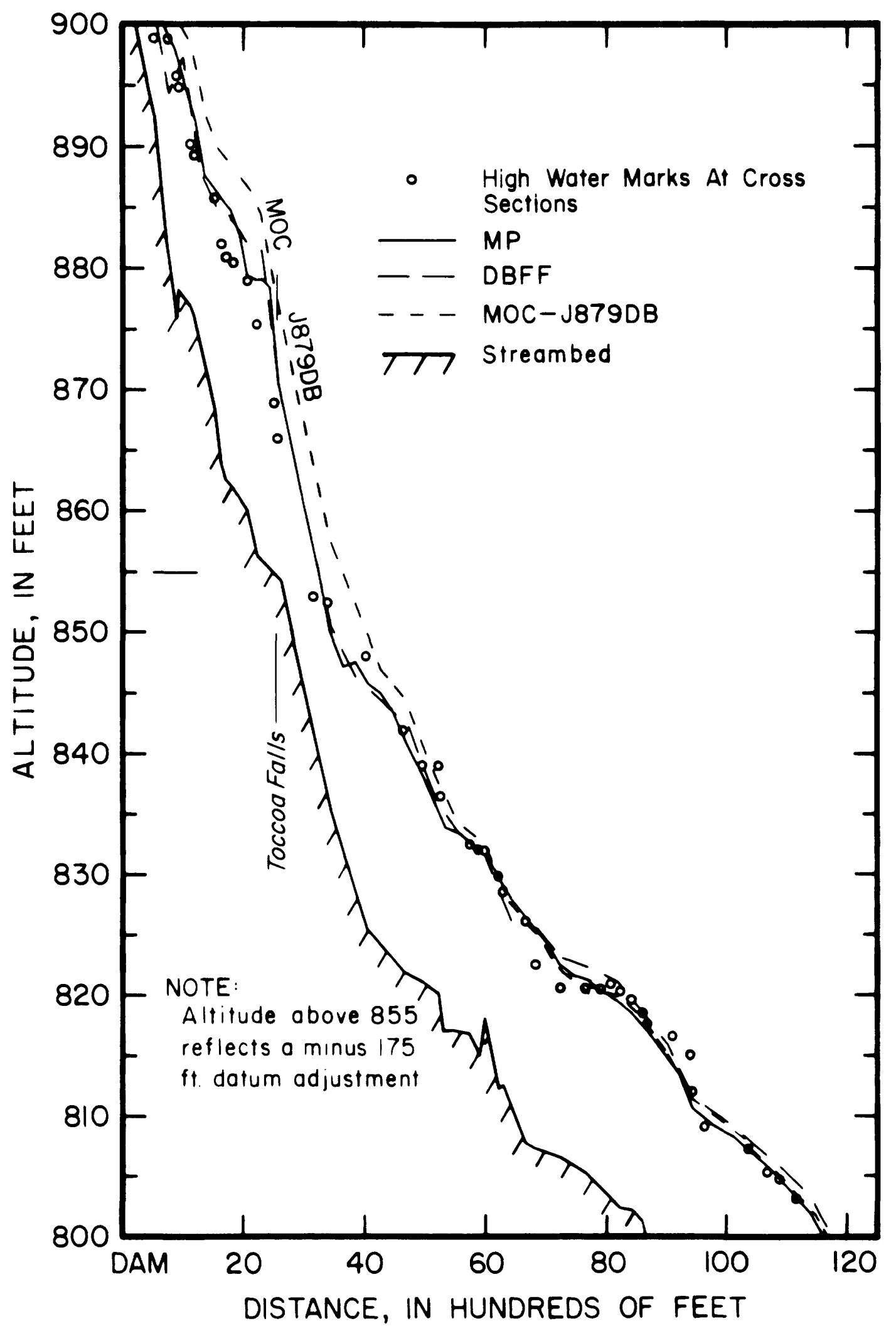

Figure 13.--Observed high-water marks and computed crests for the upper part of Toccoa Creek. 


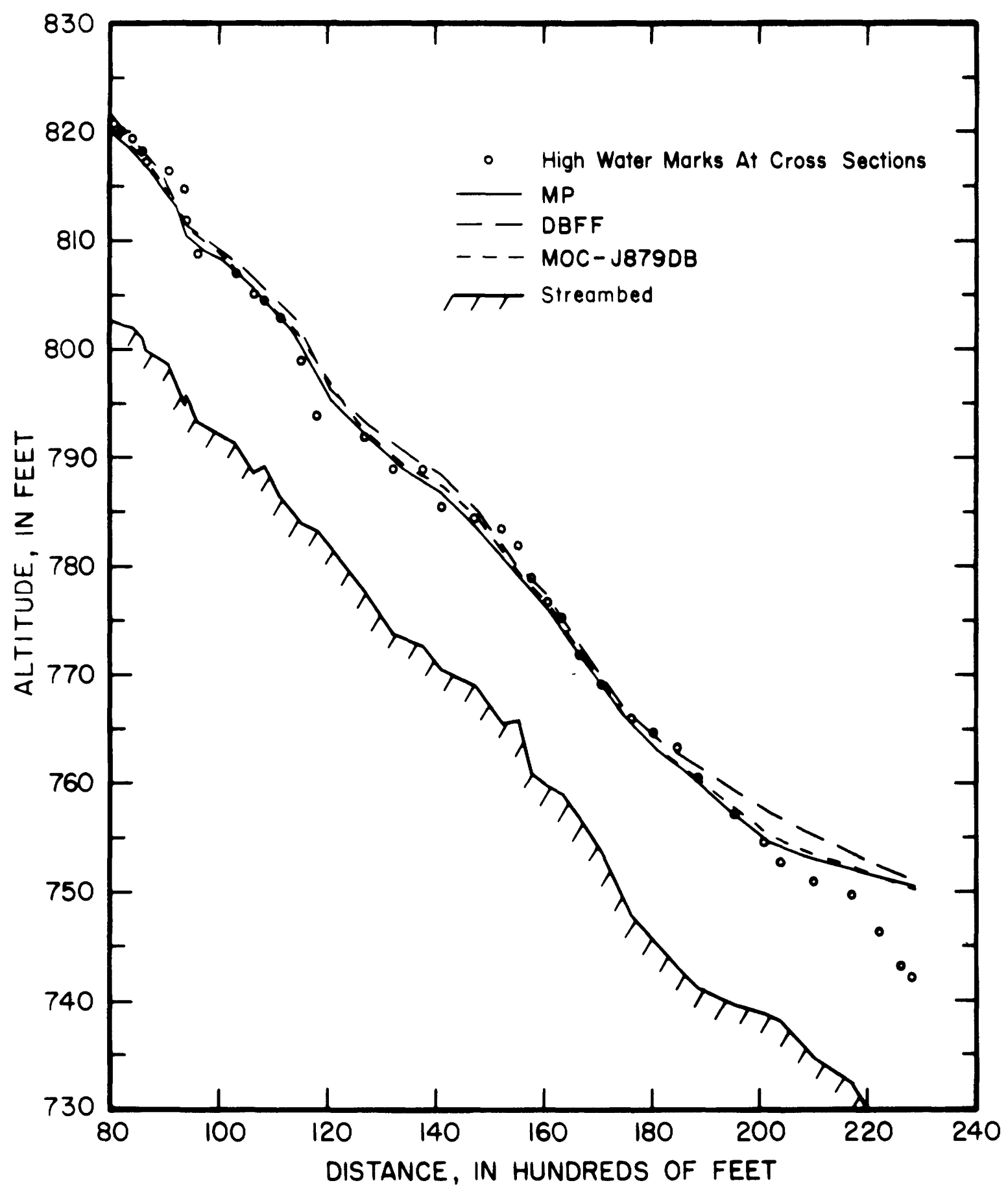

Figure 14.--Observed high-water marks and computed crests for the lower part of Toccoa Creek. 


\section{DISCUSSION}

With the presentation of the model's computed results and comparisons with observed data completed, the features of the selected dam-break models are now compared with the desirable features of a general-purpose model as discussed earlier.

One of the major features is the ability and ease of representing a particular reservoir-stream system with the model. This may include the need to represent complex geometry, outflow structures, hydraulically steep and mild slopes, and time varying inflow into the reservoir and channel. Since the MP and USTFLO models require user-supplied stageoutflow ratings at the dam, some uncertainty is encountered in developing stage-outflow relationships for the dam in the breached condition. This would be detrimental if the outflow were influenced by backwater. Furthermore, the assumptions used in the equations for breach discharge may be unreasonable for the specified condition being modeled. USTFLO and J879DB models are not programmed to simulate supercritical flow. The DBFF model will simulate subcritical and supercritical flow; however, the reach must be subdivided into subreaches having only one state of flow. As programmed, the MOC model is unable to represent complex channel geometry, such as irregular shapes, variable roughness with depth, or overbank storage. The MP, DBFE, and J879DB models use tables of depths and top widths to represent irregular shapes. Preparing these tables usually requires plotting the cross section's shape; however, the data can be taken directly from topographic maps. In order to estimate the asymmetric trapezoidal shapes for the MOC model, plotting is required. The geometric data for the USTFLO model are processed by GEDA from cross-section coordinates and stations. The only model making unusual data requirements is the MOC model. One of these requirements relates to the conveyance tube through the breach. Other requirements include reference dimensions and storm and overland flow parameters. All of the models allow time-varying inflow into the reservoir and channel.

Another major feature relates to the ease of getting the model operational, making minor adjustments for subsequent runs, and making calibration and production runs. This feature generally relates to the total number of user steps in a complete simulation and the effort in preparing sufficiently accurate input data. It also includes, for example, establishing initial conditions, adding or deleting computational nodes, changing the time step, and altering the Manning $n$. The model easiest to get running is the MP while the most difficult would be the MOC-J879DB or possibly the USTFLO. Major data alterations are likely to be required for the J879DB model. USTFLO may also require major data alterations or it may fail to function in some step. Altering most all parameters is a rather minor task in all the models. An exception can occur with the USTFLO model when the GEDA program would have to be rerun. Running the MP and DBFF models are one-step operations. The USTFLO model is usually four steps but can be more if a separate model is used to determine the initial conditions. The MOC-J879DB models require the user to perform several lengthy tasks when transferring the necessary information during the coupling step. 
Always of major concern to model users are the model's stability and accuracy. Based on the experience of testing the four models with the three data sets, the MP model was the most stable, followed by MOC, DBFF, J879DB, and USTFLO. In these tests the J879DB model often required a small time step and data alterations to achieve stability. Occasionally the USTFLO could not be stabilized or the upstream node would go dry. Although the MOC-J879DB simulations were successful, the computed results for Teton and Toccoa Falls show some irregular results.

Although no error analysis between the computed and observed data was made, it appears from the results shown in the previous figures that the DBFF model gave the best overall results. This would be followed by the MP model. The MOC-J879DB consistently computed high discharges and stages in the stream segment immediately below the dam, except for stages on Laurel Run. The MOC-J879DB model also computed considerably higher mass-balance errors than did the DBFF model.

The last feature to be discussed is user related. Reference is made to such items as simplicity, economy, readable printout, and line printer plots. For simplicity, MP and DBFF models would be preferred because they are one-step operations. When estimating computer costs by taking into account $\Delta t, \Delta x$ and the complexity of the algorithms, the MP seemed to be the least expensive, the DBFF and USTFLO seemed to be about 5 times more expensive, and the MOC-J879DB seemed to be about 50 times greater. For long reaches that would require many computational nodes the latter model has the potential of being extremely expensive. The printout from all models are relatively easy to read; however, only the DBFF and USTFLO models offer line printer plots.

\section{IDENTIFICATION OF GENERAL-PURPOSE MODEL}

One of the objectives of this investigation has been to identify the model that would be expected to perform best for most applications. On the basis of the field tests and the stated criteria for a generalpurpose model, the DBFF model has been selected. It is widely used by NWS and is also being used by other public agencies and private organizations. As stated earlier, the model that was originally supplied by the NWS and the one they currently (1979) use is heavily oriented toward real-time flood forecasting. It has been modified to better meet the needs of general-purpose applications.

\section{SUMMARY}

An evaluation of four dam-break flood wave models using three field data sets has been completed. The four models cover a wide range of sophistication and include (1) the modified Puls (MP) method, (2) the Corps of Engineers' Gradually Varied Unsteady Flow Profiles (USTFLO), an explicit finite-difference method, (3) the National Weather Service's Dam-Break Flood Forecast model (DBFF), a nonlinear implicit finitedifference method, and (4) a coupled method of characteristics (MOC) and 
a general-purpose streamflow simulation (J879DB) model which was adapted to this special application. J879DB is a linear-implicit finite-difference model. The three field data sets were from the events at Teton Dam, Idaho, Johnstown, Pa., and Toccoa Falls, Ga. The Teton Dam failure released a 265-ft head of water, producing a peak discharge of more than 2 million $\mathrm{ft}^{3} / \mathrm{s}$. Johnstown and Toccoa Falls were much 3 smaller heads, 45 and $35 \mathrm{ft}$, and peak discharges of 37,000 and $23,000 \mathrm{ft}^{3} / \mathrm{s}$, respectively.

A comparison of the model-computed discharges with determinations of peak discharges made by indirect methods shows that the model values are often within 20 percent of the latter. The most general exception is the consistently high discharges computed by the MOC-J879DB models in the stream near the dam. The ability of the models to accurately compute the flood profile was good. Except for Teton, the computed crests were most often within $2 \mathrm{ft}$ of the high-water marks. The MOC-J879DB models computed somewhat high peak stage values near the dam.

The models were also evaluated on the basis of desirable features for a general-purpose dam-break flood-wave model. The general features included (1) the ability and ease of representing a particular reservoirstream system, (2) operational characteristics, (3) stability and accuracy, and (4) user orientation. The DBFF model is considered the best overall because it most nearly fulfilled the desirable features criteria and was most accurate with field data tests. 


\section{REFERENCES CITED}

Armbruster, J. T., 1978, Model of the flooding caused by the failure of the Laurel Run Reservoir Dam, July 19-20, 1977, near Johnstown, Pennsylvania: American Meteorological Society, Conference on Flash Floods: Hydrometeorological Aspects, Los Angeles, Calif., May 2-5, 1978, 4 p.

Chen, C. L., and Armbruster, J. T., 1980, Dam-break wave model: formulation and verification. American Society of Civil Engineers, Journal of the Hydraulics Division, HY5, p. 747-767.

Chen, C. L., and Druffel, L. A., 1977, Dam-break flood wave computation by method of characteristics and linearized implicit schemes: Dam-Break Flood Routing Model Workshop, Hydrology Committee, U.S. Water Resources Council, Bethesda, Md., Oct. 18-20, 1977, Proceedings, available from U.S. Department of Commerce, National Technical Information Service, Springfield, Va. 22151 as report $\mathrm{PB}-275437$, p. 312-345.

Chow, V. T., 1964, Handbook of applied hydrology, New York, McGraw-Hill, p. 25:38-40.

Federal Investigative Board, 1977, Report of failure of Kelly Barnes Dam, Toccoa, Georgia: U.S. Army Corps of Engineers, Atlanta, Ga., $20 \mathrm{p}$.

Fread, D. L., 1971, Discussion of implicit flood routing in natural channels by M. Amerin and C. S. Fang: American Society of Civil Engineers, Journal of the Hydraulics Division, v. 97, no. HY7, p. 1156-1159.

Fread, D. L., 1977, The development and testing of a dam-break flood forecasting model: Dam-Break Flood Routing Model Workshop, Hydrology Committee, U.S. Water Resources Council, Bethesda, Md., Oct. 18-20, 1977, Proceedings, available from U.S. Department of Commerce, National Technical Information Service, Springfield, Va. 22151 as report PB-275 437, p. 164-197.

Garrison, J. M., Granju, J. P., and Price, J. T., 1969, Unsteady flow simulation in rivers and reservoirs: American Society of Civil Engineers, Journal of the Hydraulics Division, v. 95, no. HY5, p. 1159-1176.

Gundlach, D. L., and Thomas, W. A., 1977, Guidelines for calculating and routing a dam-break flood: Davis, California, U.S. Army Corps of Engineers Hydrologic Engineering Center Research Note, no. 5, 13 p.

Keefer, T. N., 1976, Comparison of linear systems and finite-difference flow-routing techniques: Water Resources Research, v. 12, no. 5, p. 997-1006. 
Land, L. F., 1978a, Analysis of flood resulting from the Toccoa Falls, Georgia, dam-break: American Meteorological Society, Conference on Flash Floods: Hydrometeorological Aspects, May 2-5, 1978, Los Angeles, California, p. 127-130.

Land, L. F., 1978b, Unsteady streamflow simulation using a linear implicit finite-difference model: U.S. Geological Survey WaterResources Investigations 78-59, 59 p.

Price, J. T., Lowe, G. W., and Garrison, J. M., 1977, Unsteady flow modeling of dam-break waves: Dam-Break Flood Routing Model Workshop, Hydrology Committee, U.S. Water Resources Council, Bethesda, Md., Oct. 18-20, 1977, Proceedings, available from U.S. Department of Commerce, National Technical Information Service, Springfield, Va. 22151 as report PB-275 437, p. 89-130.

Ray, H. A., and Kjelstrom, L. C., 1978, The flood in southeastern Idaho from the Teton Dam failure of June 5, 1976: U.S. Geological Survey Open-File Report 77-765, 48 p.

Sanders, C. L., Jr., and Sauer, V. B., 1979, Kelly Barnes Dam flood of November 6, 1977, near Toccoa, Georgia: U.S. Geological Survey Hydrologic Investigations Atlas 613.

Soil Conservation Service, 1972, Flood routing: National engineering handbook, sec. 4, Hydrology, chap. 17, U.S. Department of Agriculture, p. 17-1 - 17-93.

U.S. Army Corps of Engineers, 1973, HEC-1 flood hydrograph package: Davis, California, Hydrologic Engineering Center Computer Program 723-S6-L2010, 25 p.

U.S. Army Corps of Engineers, 1976, Geometric elements from cross-section coordinates: Davis, California, Hydrologic Engineering Center Computer Program 723-G2-L 745 B, 15 p.

U.S. Army Corps of Engineers, 1977, Gradually varied unsteady flow profiles: Davis, California, Hydrologic Engineering Center Computer Program 723-G2-L7450, 32 p. 
Table 1.--Flow into the three reservoir-stream-systems

\begin{tabular}{|c|c|c|c|}
\hline Site & (date and & hour) & $\begin{array}{c}\text { Discharge } \\
(\mathrm{ft} / \mathrm{s})\end{array}$ \\
\hline Teton Dam Reservoir & $5-5-76$ & $\begin{array}{l}0000 \\
2400\end{array}$ & $\begin{array}{l}3,600 \\
3,600\end{array}$ \\
\hline Laurel Run Reservoir ${ }^{1}$ & $\begin{array}{l}7-19-77 \\
7-20-77\end{array}$ & $\begin{array}{l}2110 \\
2200 \\
2300 \\
2400 \\
0100 \\
0210 \\
0225 \\
0300 \\
0400 \\
0500 \\
0600 \\
0700\end{array}$ & $\begin{array}{r}15 \\
180 \\
900 \\
2,300 \\
4,400 \\
11,000 \\
11,000 \\
6,800 \\
2,600 \\
1,000 \\
310 \\
100\end{array}$ \\
\hline Red Run ${ }^{1}$ & $7-20-77$ & $\begin{array}{l}1130 \\
2200 \\
2300 \\
2400 \\
0100 \\
0145 \\
0300 \\
0400 \\
0500\end{array}$ & $\begin{array}{r}10 \\
55 \\
410 \\
560 \\
1,200 \\
3,900 \\
970 \\
230 \\
50\end{array}$ \\
\hline Wild Cat Run ${ }^{1}$ & $7-20-77$ & $\begin{array}{l}2130 \\
2200 \\
2300 \\
2330 \\
0100 \\
0200 \\
0300 \\
0400 \\
0500 \\
0600 \\
0700\end{array}$ & $\begin{array}{r}10 \\
70 \\
600 \\
1,000 \\
700 \\
640 \\
800 \\
2,400 \\
700 \\
160 \\
28\end{array}$ \\
\hline Toccoa Falls Reservoir ${ }^{1}$ & $11-6-77$ & $\begin{array}{l}1700 \\
1900 \\
2000 \\
2030 \\
2100 \\
2200 \\
2300 \\
2400 \\
0100 \\
0200\end{array}$ & $\begin{array}{r}25 \\
420 \\
930 \\
980 \\
920 \\
720 \\
540 \\
410 \\
310 \\
240\end{array}$ \\
\hline
\end{tabular}

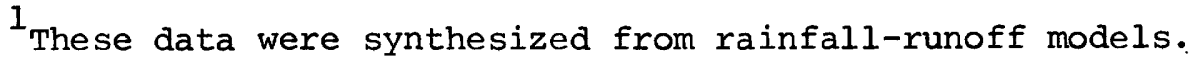
Peaks were adjusted to indirect measurements. 
Table 2.--Relationship of elevation-storage-surface area-outflow for the three reservoirs

\begin{tabular}{|c|c|c|c|c|}
\hline Reservoir & $\begin{array}{c}\text { Elevation } \\
\text { (ft) }\end{array}$ & $\begin{array}{c}\text { Storage } \\
(\text { acre-ft) }\end{array}$ & $\begin{array}{c}\text { Surface Area } \\
\text { (acre) }\end{array}$ & $\begin{array}{l}\text { Outflow } \\
\left(f t^{3} / s\right)\end{array}$ \\
\hline Teton $^{1}$ & $\begin{array}{l}5,025 \\
5,050 \\
5,075 \\
5,100 \\
5,125 \\
5,150 \\
5,175 \\
5,200 \\
5,225 \\
5,250 \\
5,275 \\
5,300 \\
5,320\end{array}$ & $\begin{array}{r}0 \\
2,000 \\
7,000 \\
17,000 \\
32,000 \\
51,000 \\
75,000 \\
101,000 \\
133,000 \\
168,000 \\
208,000 \\
251,000 \\
285,000\end{array}$ & $\begin{array}{r}0 \\
160 \\
240 \\
560 \\
640 \\
880 \\
960 \\
1,200 \\
1,350 \\
1,500 \\
1,650 \\
1,800 \\
1,950\end{array}$ & \\
\hline Laurel Run & $\begin{array}{l}1,392 \\
1,400 \\
1,405 \\
1,410 \\
1,415 \\
1,420 \\
1,425 \\
1,430 \\
1,435 \\
1,440\end{array}$ & $\begin{array}{r}0 \\
1 \\
5 \\
29 \\
68 \\
126 \\
208 \\
300 \\
425 \\
570\end{array}$ & $\begin{array}{r}0 \\
.1 \\
3.1 \\
6.2 \\
9.3 \\
15.1 \\
18.5 \\
22.3 \\
25.4 \\
29.8\end{array}$ & $\begin{array}{r}0 \\
0 \\
0 \\
0 \\
0 \\
0 \\
0 \\
0 \\
3,100 \\
10,000+\end{array}$ \\
\hline Toccoa Falls & $\begin{array}{l}1,102 \\
1,120 \\
1,125 \\
1,130 \\
1,135 \\
1,140 \\
1,142\end{array}$ & $\begin{array}{r}0 \\
6 \\
52 \\
166 \\
333 \\
551 \\
643\end{array}$ & $\begin{array}{r}0 \\
4.1 \\
15.3 \\
28.6 \\
38.3 \\
47.4 \\
51.0\end{array}$ & \\
\hline
\end{tabular}

${ }^{l}$ Estimated from reservoir capacity curve given by Gundlach and Thomas (1977). 
Table 3.--Channel characteristic and geometry data coded in the GEDA format for the Teton Dam reservoir-stream system. The cross-section's high-water elevation is coded in the last field of the $\mathrm{Xl}$ card.

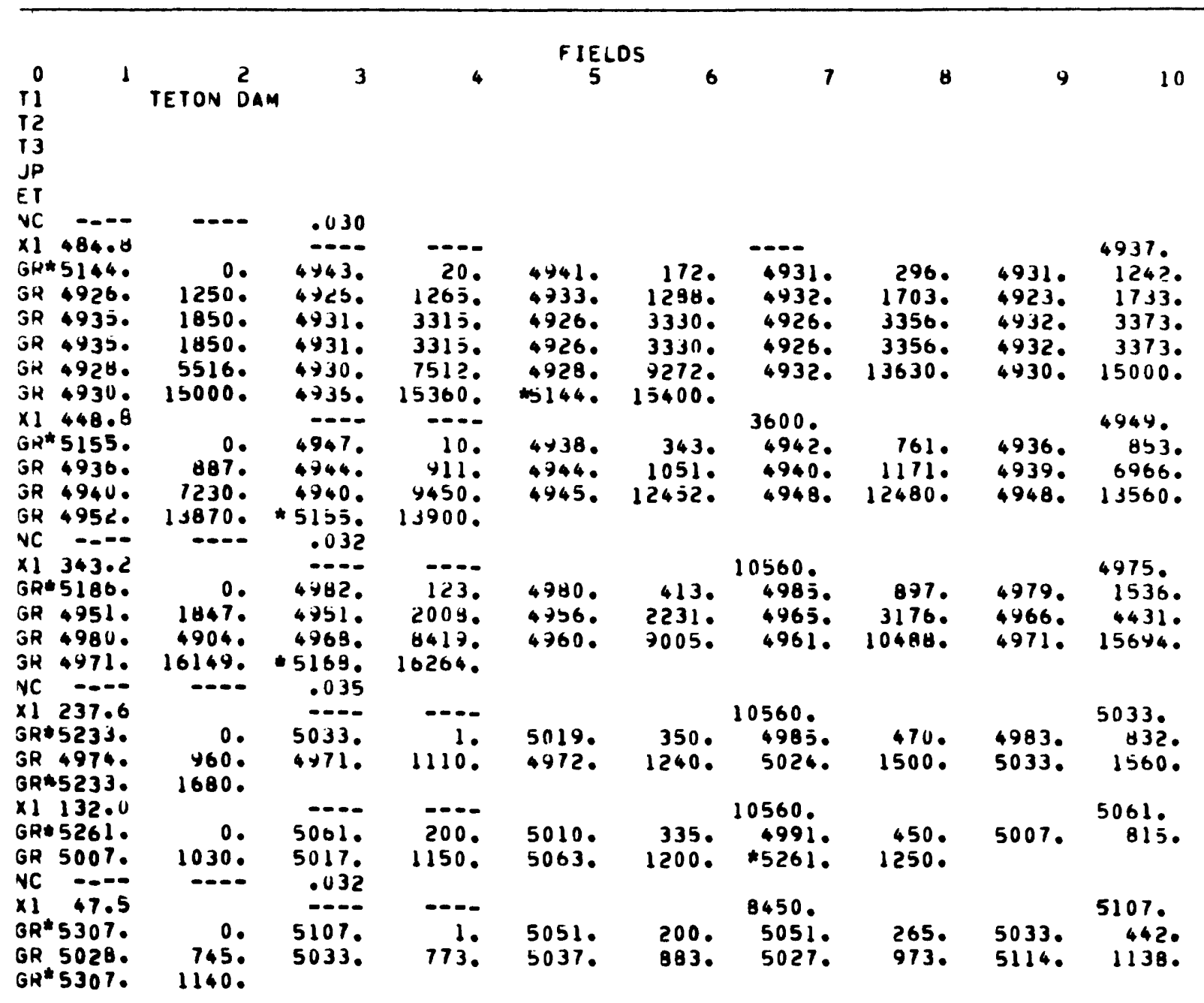


Table 3.--Channel characteristic and geometry data coded in the GEDA format for the Teton Dam reservoir-stream system. The cross-section's high-water elevation is coded in the last field of the $\mathrm{Xl}$ card--Continued

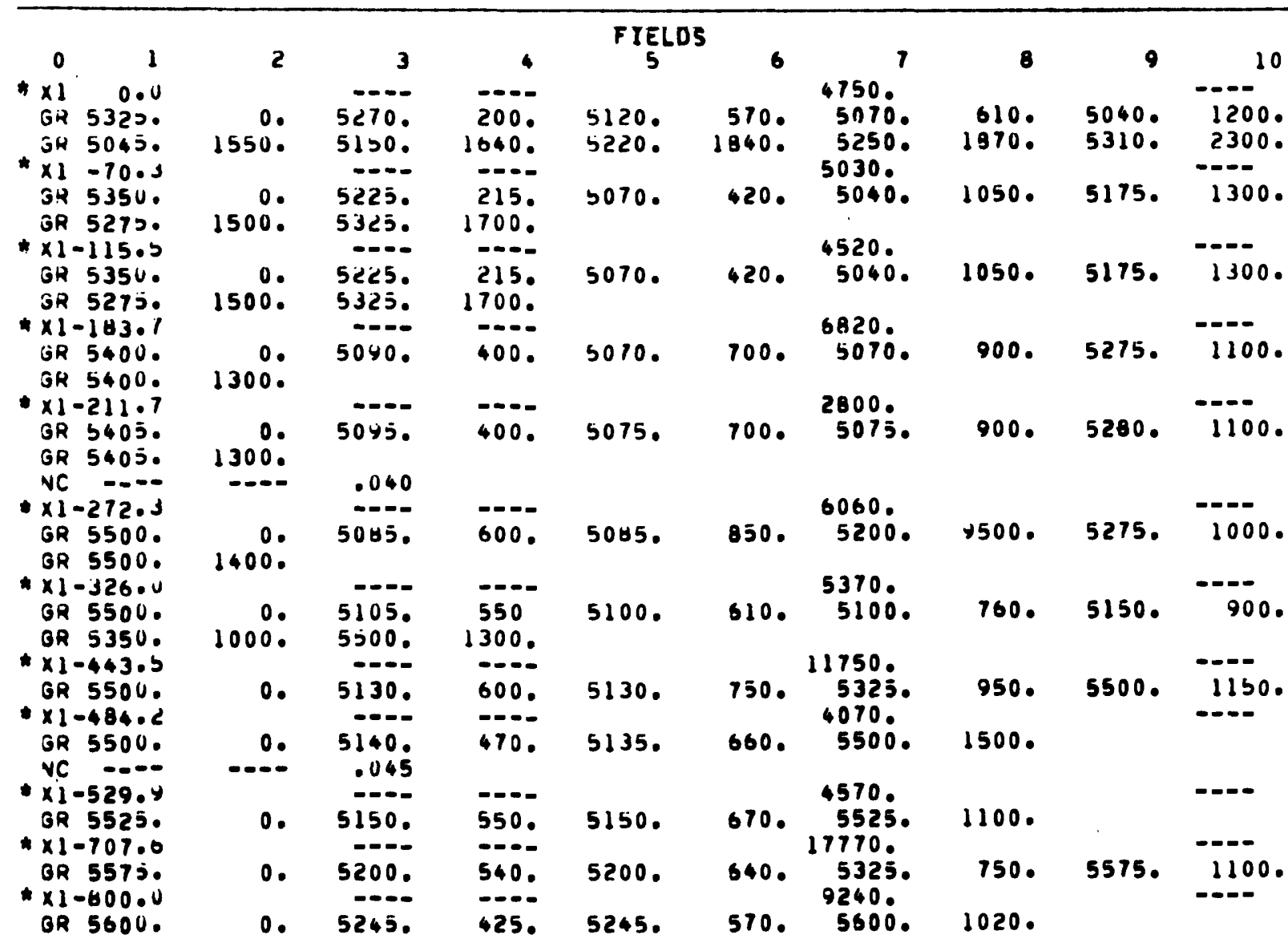


Table 4.--Channel characteristic and geometry data coded in the GEDA format for the Laurel Run reservoir-stream system. The cross section's highwater elevation is coded in the last field of the Xl card.

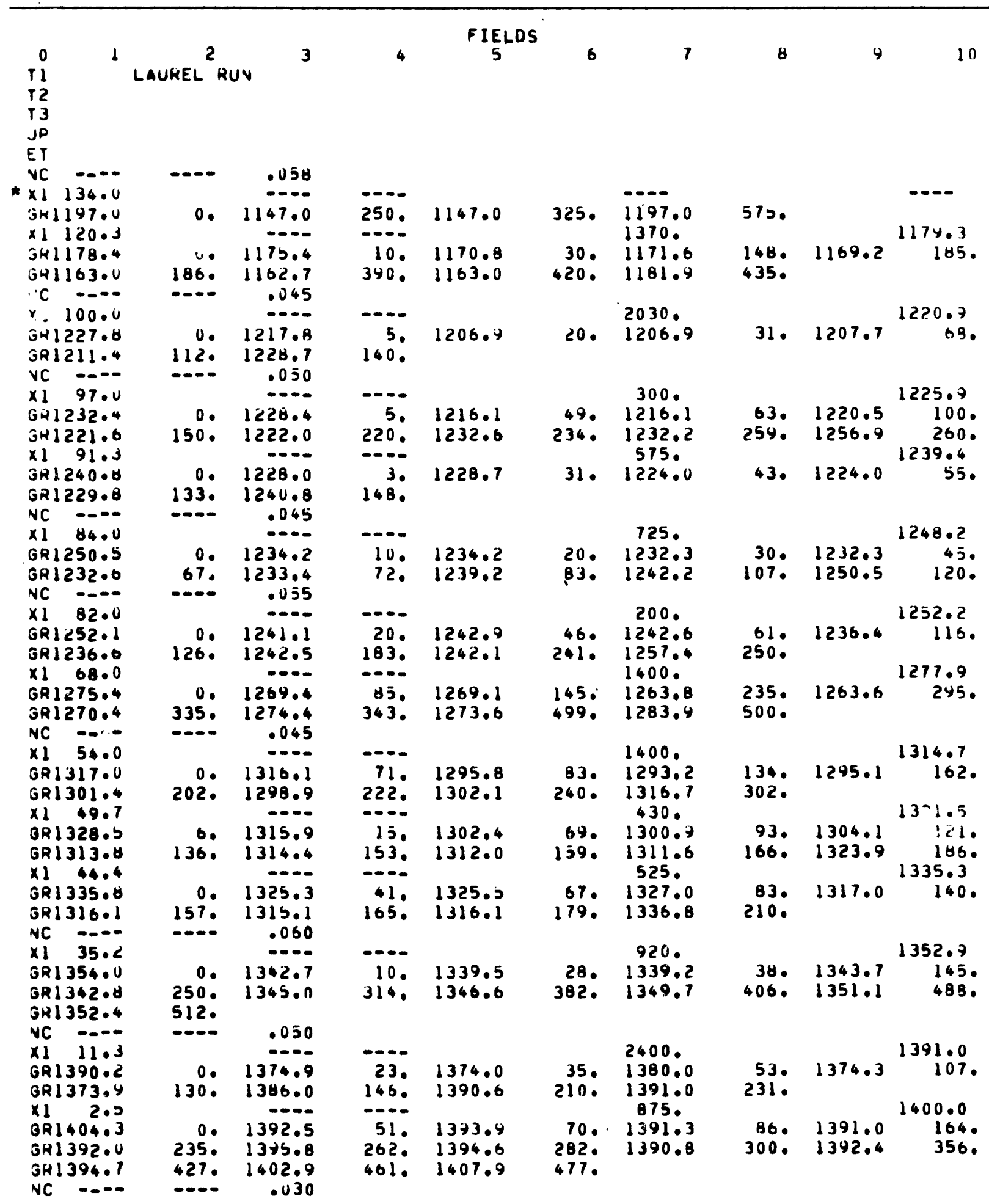


Table 4.--Channel characteristic and geometry data coded in the GEDA format for the Laurel Run reservoir-stream system. The cross-section's highwater elevation is coded in the last field of the XI card--Continued

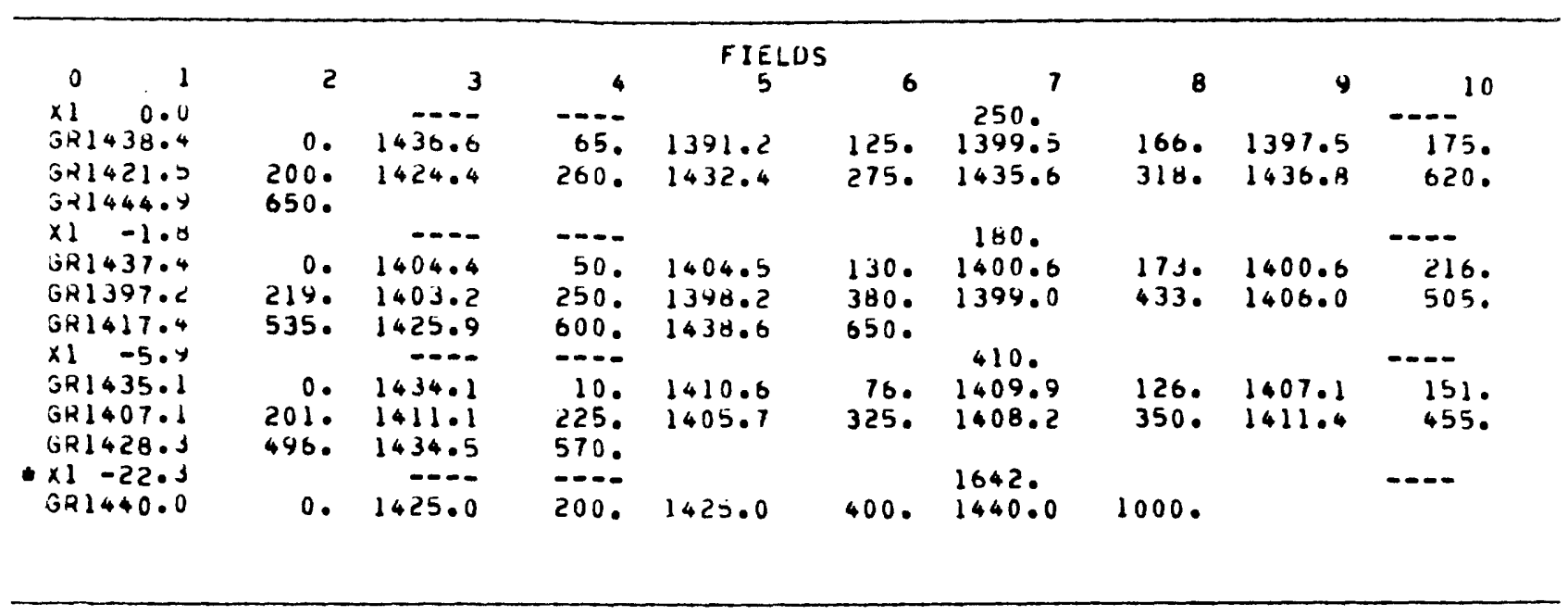


Table 5.--Channel characteristic and geometry data coded in the GEDA format for the Toccoa Falls reservoir-stream system. The cross section's highwater elevation is coded in the last field of the XI card

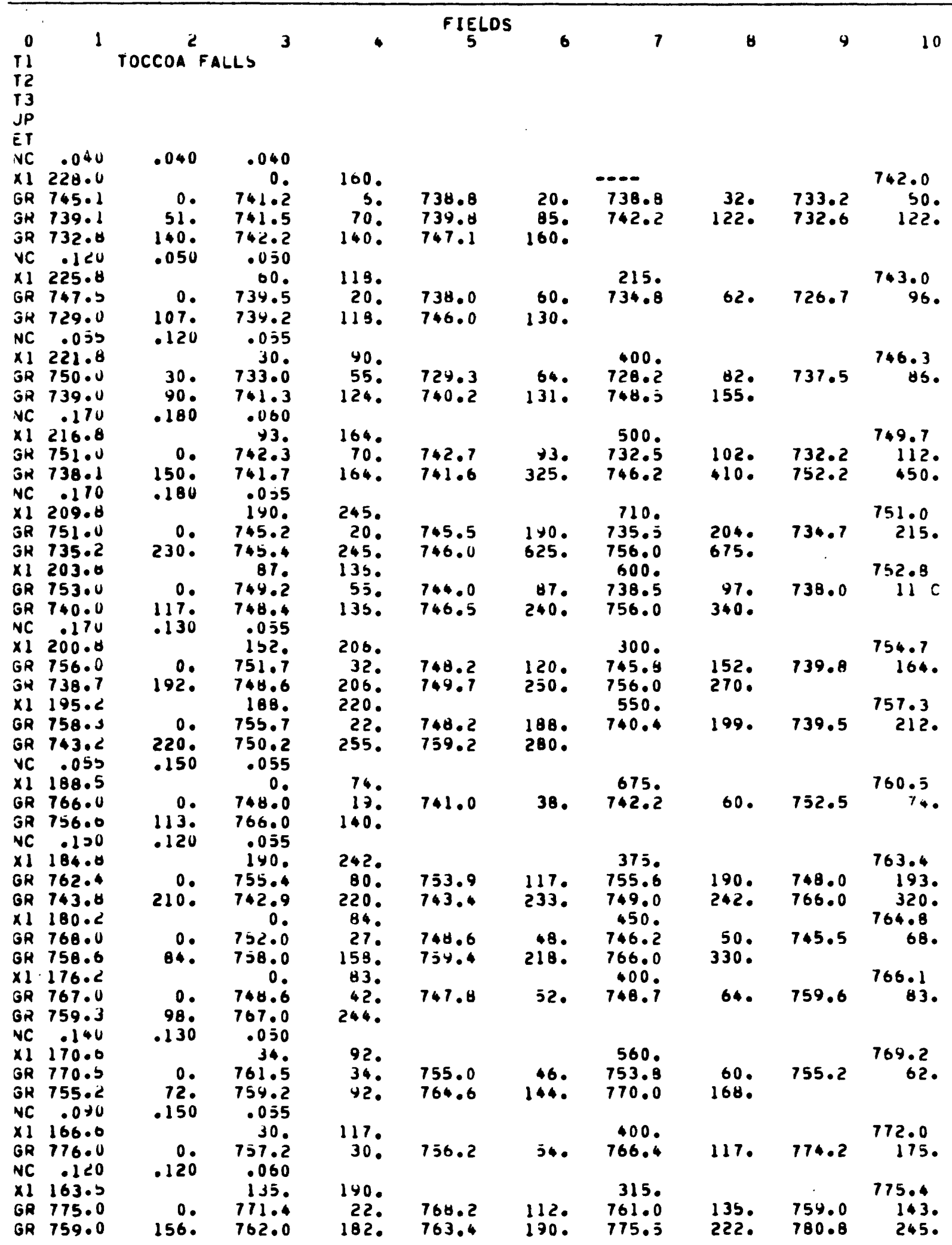


Table 5.--Channel characteristic and geometry data coded in the GEDA format for the Toccoa Falls reservoir-stream system. The cross section's highwater elevation is coded in the last field of the $\mathrm{xl}$ card--Continued

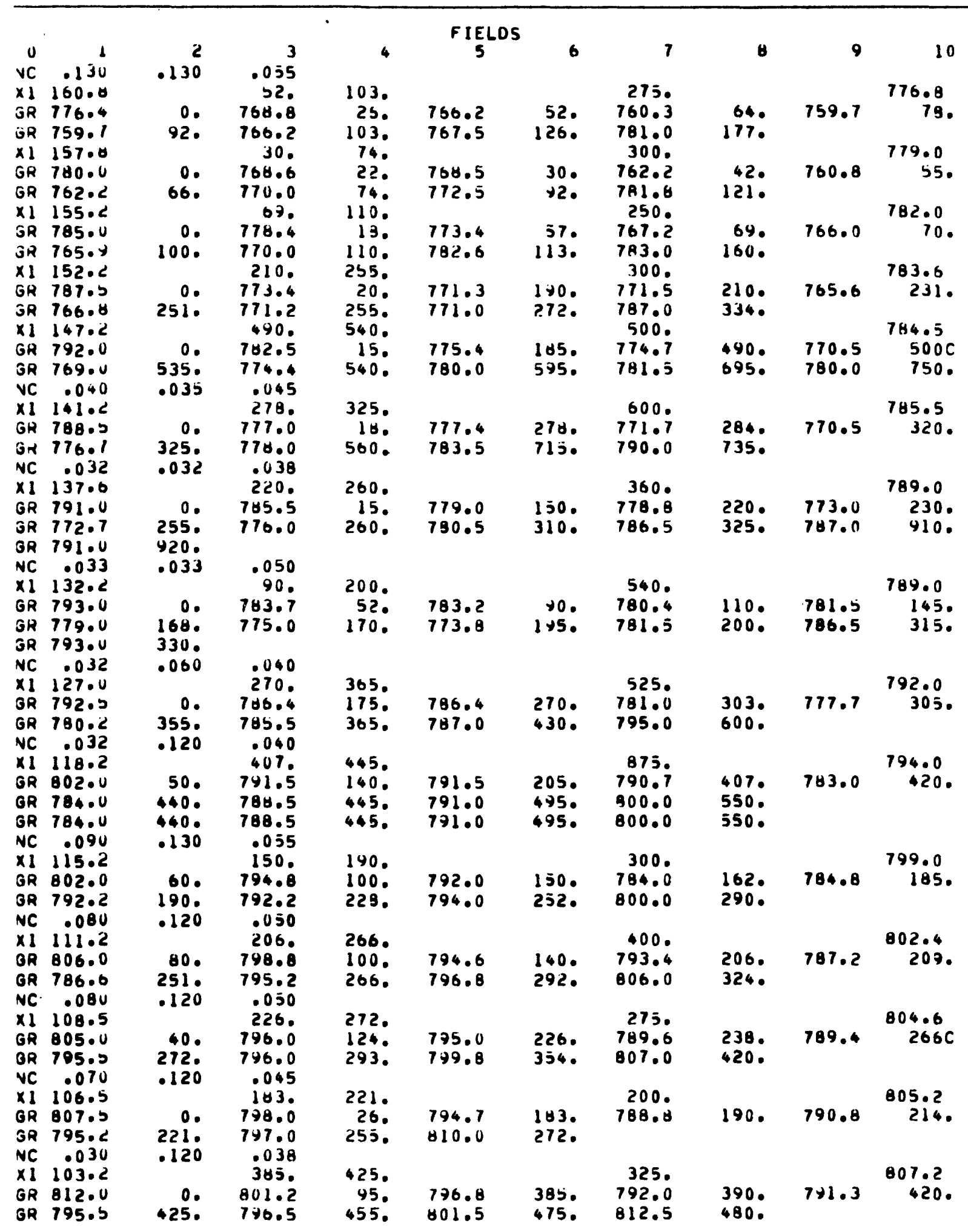


Table 5.--Channel characteristic and geometry data coded in the GEDA format for the Toccoa Falls reservoir-stream system. The cross section's highwater elevation is coded in the last field of the $\mathrm{XI}$ card--Continued

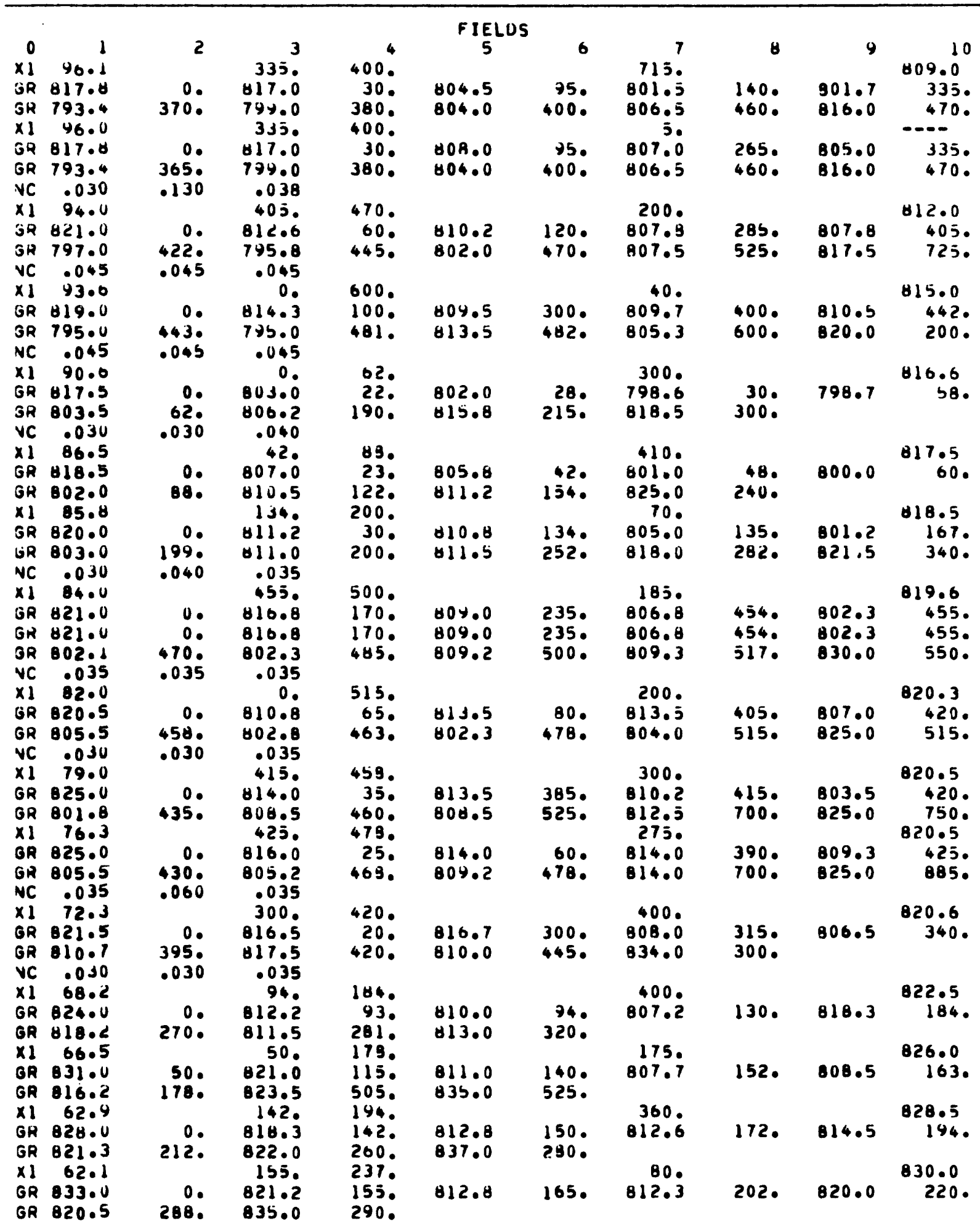


Table 5.--Channel characteristic and geometry data coded in the GEDA format for the Toccoa Falls reservoir-stream system. The cross section's highwater elevation is coded in the last field of the Xl card--Continued

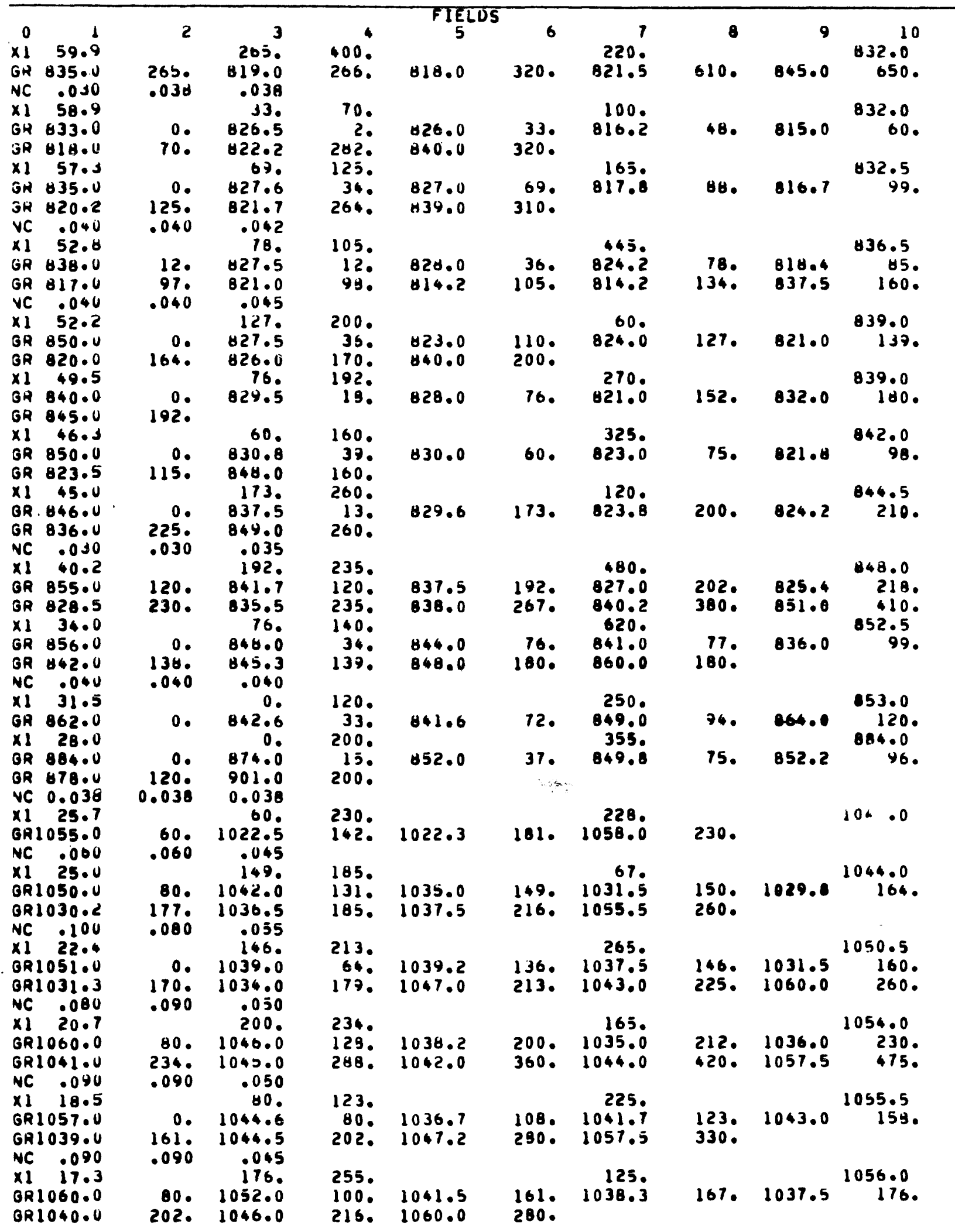


Table 5.--Channel characteristic and geometry data coded in the GEDA format for the Toccoa Falls reservoir-stream system. The cross section's highwater elevation is coded in the last field of the XI card--Continued

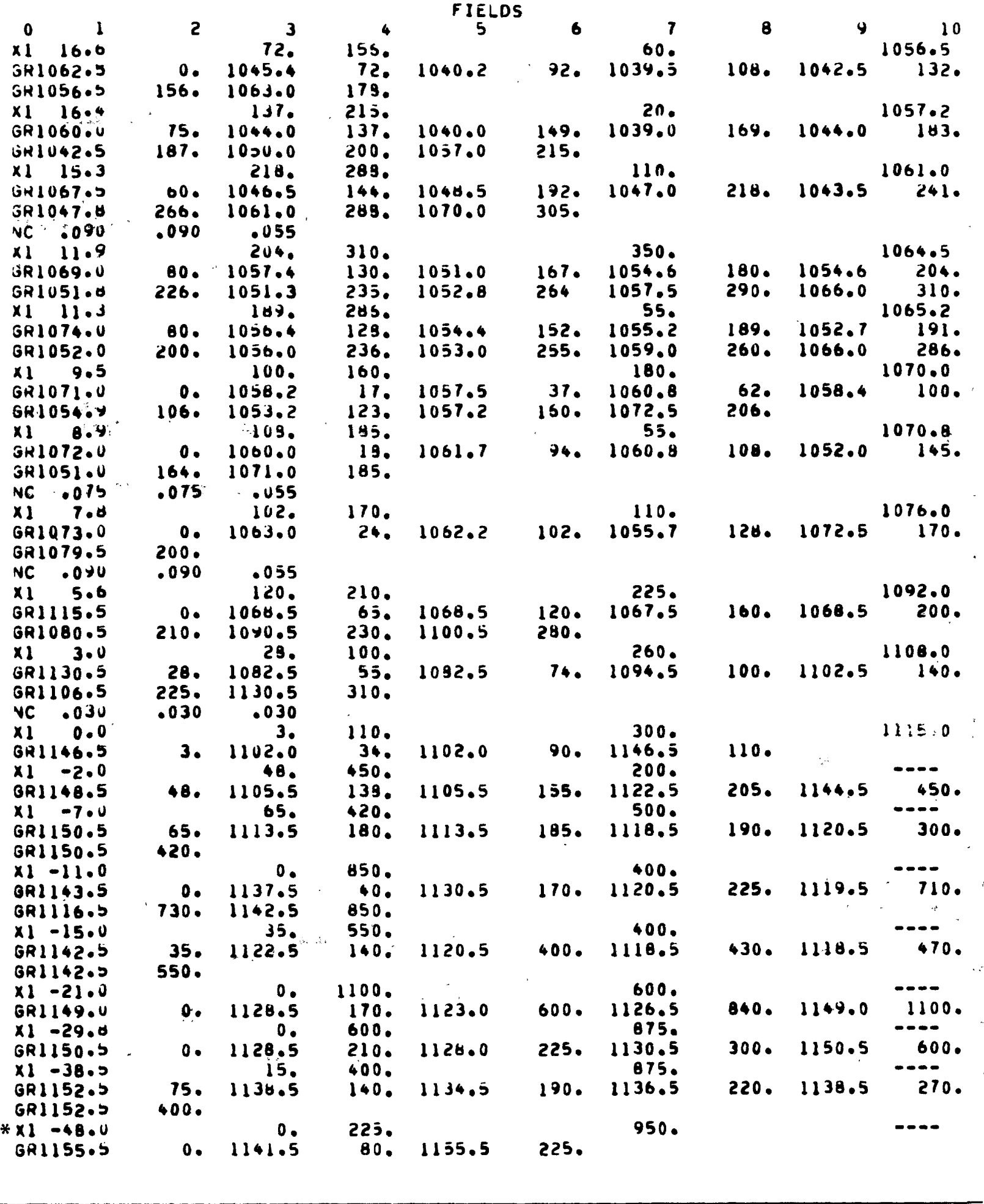


Table 6.--Code format and variable definitions of the data given in tables 3-5.

CANDS DEFININS FIELD DATA

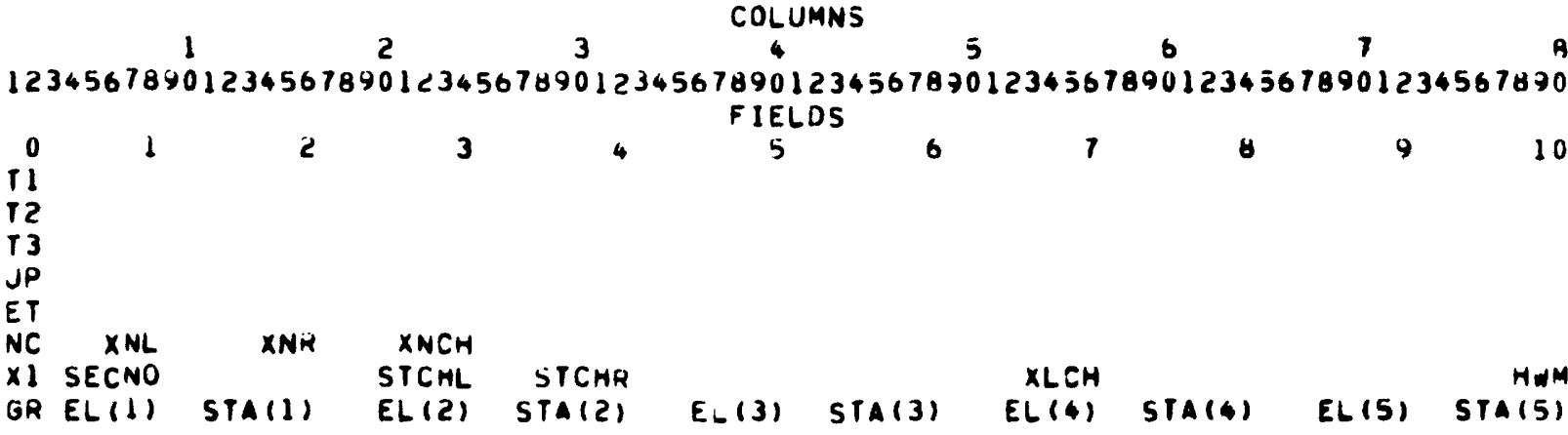

DEFINITIONS:

DEFITIONS:

CARO TYPES:

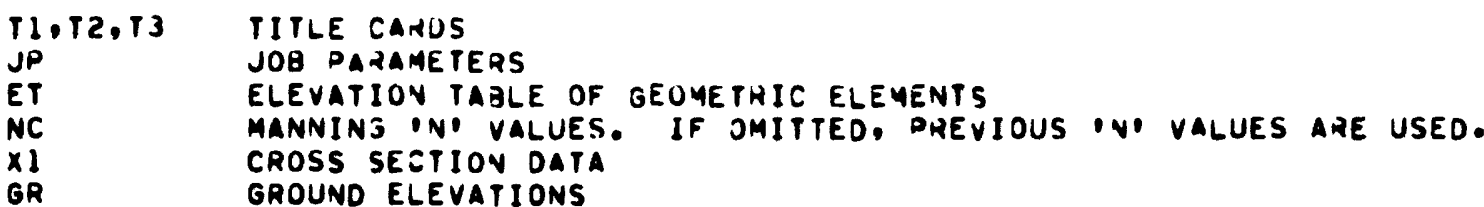

VARIABLES:

XNL. MANNING ON FOR LEFT OVEPBANK

XNR MANNING ONP FOR RIGHT OVEKBAVK

XNCH MANNING ON FOP CHANNE.

SECNO SECTION NUMBER, CODED IN HUNDREUS OF FEET DOWNSTREAM FHOY DAM

STCHL STATION AT POINT CONNECTING LEFT BAVK ANJ MAIN CHANYEL

STCHR STATION AT POIVT CONNECTING PIGHT BANK A YO MAIV CHAVVEL

XLCH OISTANCE BETWEEN THIS AVJ ADJACEVT JONNSTREAY CHOSS SECTION

HWM ELEVATION OF HIGH WATER MARK, VOT SPECIFIED OY GEDA

ELI, ELEVATION OF COORDINATE PUINT IN CROSS SECTION

STAI, STATION OF COOADINATE POINT, IN EEET FZON LEFT, LOOKING DONNSTREAM 


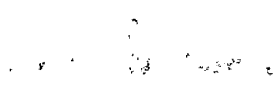


Table 6.--Code format and variable definitions of the data given in tables 3-5.

CARDS DEFININS FIELD DATA

CARDS DEFININS FIELO DATA

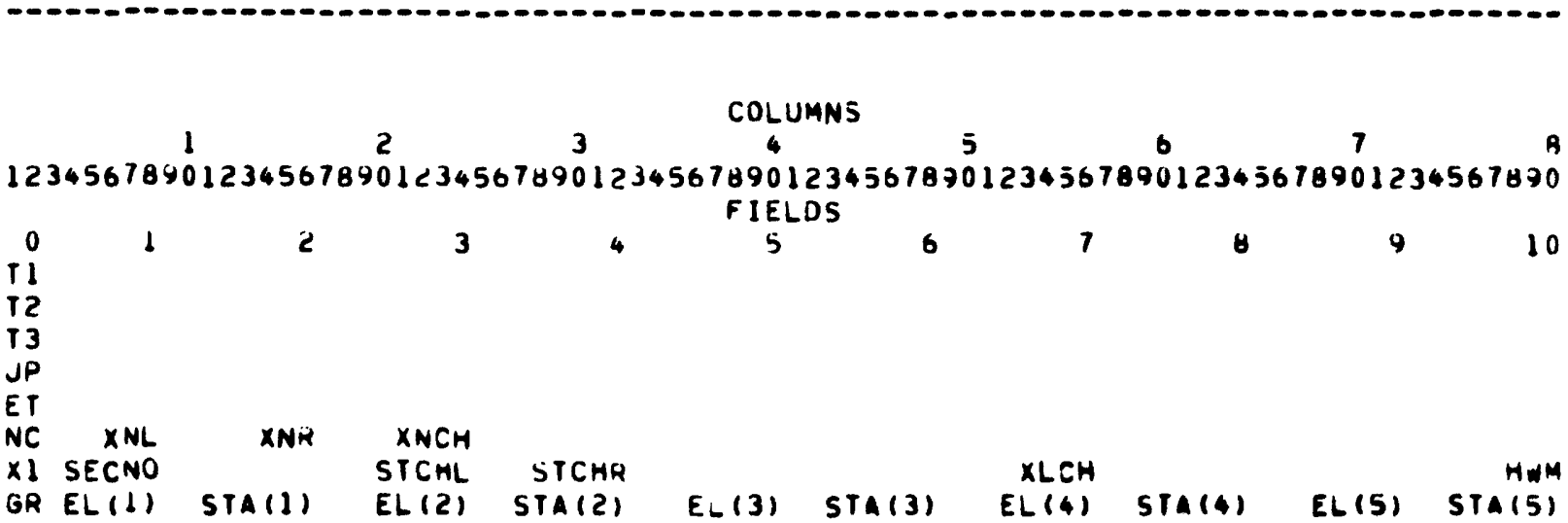

DEFINITIONS:

$-\infty-\infty$

CARO TYPES:

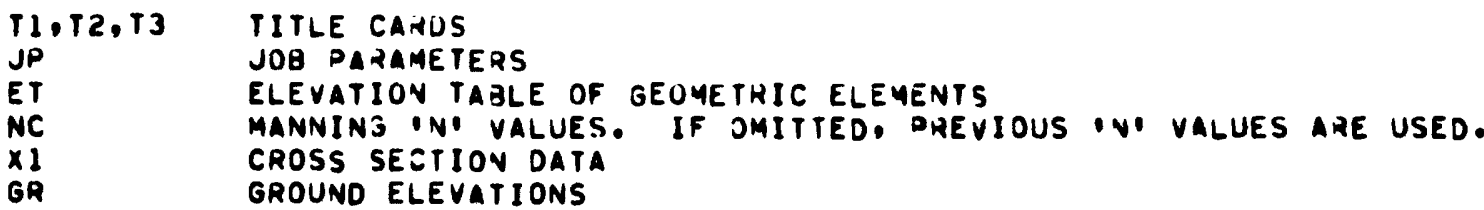

VARIABLES

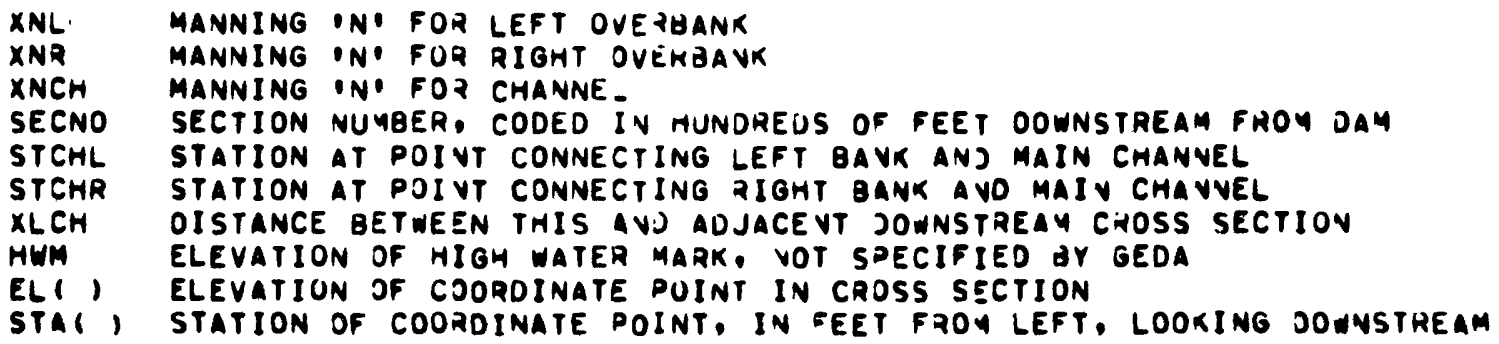

